\title{
EXPERIENCIA ESTÉTICA Y FORMULACIÓN CIENTÍFICA: EL CASO DEL HARMONICES MUNDI DE JOHANNES KEPLER
}

\author{
AESTHETIC EXPERIENCE AND SCIENTIFIC FORMULATION: THE CASE \\ OF THE HARMONICES MUNDI BY JOHANNES KEPLER
}

\author{
Carlos Calderón Urreiztieta \\ Universitat Pompeu Fabra ${ }^{1}$
}

\begin{abstract}
Resumen:
La música como modelo explicativo del universo ha estado presente desde el mismo nacimiento de la reflexión filosófica. En el caso de Kepler, la música y la astronomía quedaban homologadas sobre la base de un único arquetipo geométrico, y por ello podían compartir sus observaciones, teorías e, incluso, emotividades. Las condiciones históricas que posibilitaron esta interconexión están fundamentadas en la sólida formación musical de Kepler, su interés por la polifonía de sus contemporáneos y, en especial, por la música de Orlando di Lasso. Visto así, una experiencia estética musical, permitió a Kepler configurar un marco de verdades sobre el que formuló y contrastó sus teorías; tal como puede leerse - y escucharse- en los mismos textos del Harmonices Mundi. Enlace fundamental para este ensayo: http://www.calderon-online.com/anuariomusical/kepler/
\end{abstract}

Palabras clave:

Kepler; ciencia; matemáticas; astronomía; planeta; Lasso; armonía; polifonía; motete; durus; mollis; estética; siglo XVII.

\begin{abstract}
:
Music as an explanatory model of the universe has been around since the very birth of philosophical thought. For Kepler, music and astronomy were homologated on the basis of a single geometric archetype, and so they could share their observations, theories and even emotivism. The historical conditions that enabled this interconnection are based on Kepler's solid musical education, his interest in contemporary polyphony and, especially, by the music of Orlando di Lasso. Seen this way, a musical
\end{abstract}

1 Este artículo está basado en el Trabajo de Investigación que fuera presentado ante la Universidad de Barcelona, para la obtención del Diploma de Estudios Avanzados, DEA, en el marco del Doctorado Interuniversitario UB-UAB-UPF de Historia de las Ciencias, en el año 2005, bajo la dirección del Dr. Antoni Malet. Agradezco, particularmente, la lectura y revisión general del presente ensayo, al Dr. Antonio Ezquerro y su interés por encontrar y evidenciar espacios comunes entre la historia de la ciencia y la musicología. En este sentido, se escribe, tanto para musicólogos como para historiadores de la ciencia, razón por la cual se han añadido cuestiones aquí (datos biográficos sobre músicos, filósofos naturales o científicos, junto a aclaratorias de algunos conceptos básicos de ambas disciplinas), que quizás, no serían necesarias para unos especialistas concretos. Por tanto, se ruega al lector que tenga presente el ánimo con que han sido añadidos, pues sólo intentan precisar para unos, lo que puede ser harto sabido para otros. 
aesthetic experience, enabled Kepler set a framework of truths on which his theories could be formulated and contrasted, as can be read -and listen - in the same texts of Harmonices Mundi. Fundamental link to this essay: http://www.calderon-online.com/ anuariomusical/kepler/

\section{Keywords:}

Kepler; science; mathematics; astronomy; planet; Lasso; harmony; polyphony; motet; durus; mollis; aesthetics; $17^{\text {th }}$ century.

\section{INTRODUCCIÓN}

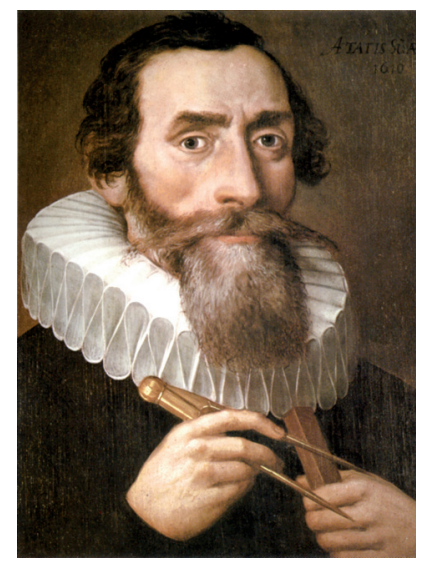

Figura 1. Johannes Kepler (*Weil der Stadt, 1571; †Regensburg, 1630).

Retrato anónimo (hacia 1610) en el observatorio de la ciudad de Kremsmuenster en Austria

Para nadie es un secreto que Johannes Kepler suscita encontradas posiciones en torno a la naturaleza de su obra y su propia vida, pues, al igual que la mayoría de los filósofos naturales del siglo XVII, es percibido como un Jano bifronte: un personaje cuya obra se configura sobre una mirada retrospectiva de los saberes antiguos a la par de otra que señala la fundación de unos nuevos y radicales saberes modernos. ${ }^{2}$ En el caso particular de Kepler confluyen -como tal vez en ningún otro-

2 El término 'filosofía natural' se utiliza aquí en el contexto habitual de la historia de la ciencia, es decir, como el conjunto de actividades, que para el siglo XVII, se consideran hoy como investigación científica y que involucran la observación, la experimentación física, la descripción cualitativa y sus intentos de formalización cuantitativa y matemática; todo esto mezclado con la reflexión filosófica que indaga las causas del mundo natural. Entre estas actividades se encontraban las propias de astrónomos, matemáticos y músicos teóricos, los cuales se referían, a menudo, a la música como parte de la filosofía o como una actividad física y filosófica. Respecto a la metáfora del "Jano bifronte" es menester agregar que Jano, dios encargado de las puertas del Tiempo (pasado - porvenir), las abría, solamente, en tiempos de guerra, y Kepler -coincidencia fortuita- escribió y publicó su magna obra marcado por los tumultuosos acontecimientos de la Guerra de los Treinta Años. Entre la pléyade de filósofos naturales del siglo XVII, y entre los que han recibido esta caracterización metafórica, tal vez sea Kepler quien mejor la encarne. 
Principios teológicos y físicos, inducción y deducción, la veneración incondicional de los hechos y una fuerte tendencia al conocimiento apriorístico, especulaciones teológicas y matemáticas, concepciones platónicas y aristotélicas, todo ello se entrecruza y enmaraña en su mente. ${ }^{3}$

Esta confluencia, que puede resumirse en una concepción del mundo que es, a la vez, estética, teológica, mística, metafísica y física, alcanza su mayor representatividad en la obra Harmonices Mundi, en la cual Kepler mostraba la mayor cantidad de datos que hubiera venido recopilando a lo largo de su vida. ${ }^{4}$ Como señalaba Caspar, un Kepler "arrebatado y poseído" por el espectáculo celeste, produjo un libro que con habilidad matemática, con minuciosidad de artesano y con sensibilidad de poeta mostraba una compleja estructura argumental que justificaba, estéticamente a priori, el porqué el cosmos era así y no de otra manera.

Entre los pilares de ese edificio de razonamientos se encontraban las disciplinas de la armonía y la música, entendida esta última en el sentido del siglo XVII y, en especial, bajo lo que Kepler denominaba música moderna figurada, es decir, la polifonía vocal de su propio tiempo. ${ }^{5}$

Como es sabido, en la base del Quadrivium medieval y renacentista, y al lado de la aritmética, la astronomía y la geometría, se encontraba también la música, y ésta era considerada como un contexto nomológico verdadero donde contrastar las especulaciones filosóficas naturales. Es decir, al igual que el tetractys $^{6}$, el ángulo recto, o la perfección de las esferas celestes, la ratio sonora nos ponía en contacto con

3 La biografía de referencia principal sobre Johannes Kepler es la realizada por el matemático e historiador de la astronomía Max Caspar (*Friedrichshafen, 1880; †Munich, 1956) cuya primera edición en alemán fue: CASPAR, 1941. La cita está extraída de la traducción al castellano: CASPAR, 2003: 87.

4 KEPLER, 1619. Una versión digitalizada facsímil (formato $p d f$ ), puede leerse o descargarse (en diversos formatos) en http://archive.org/details/ioanniskepplerih00kepl (Revisado el 07-09-2012). La edición de referencia principal del Harmonices Mundi se encuentra como un volumen íntegro -Vol. 6- dentro del compendio de obras editado por Max Caspar: KEPLER, 1937. La traducción más reciente y reconocida por los historiadores de la ciencia es la realizada por Eric Aiton, Allistair Duncan y Judith Field: KEPLER, 1997. De aquí en adelante las citas al Harmonices Mundi de Kepler harán siempre referencia a estas tres obras así: KEPLER, 1619, libro: página; 1937, volumen: página; 1997: página.

5 Durante la antigüedad y hasta el siglo XVII los términos 'armonía' y 'música', si bien no pueden ser totalmente intercambiables, muchas veces operan como sinónimos. En la antigua escuela pitagórica el término 'armonía' devino en una idea abstracta de orden y belleza fundamentada en el número, pero en el ámbito estrictamente musical, el término 'armonía' aparecía en los tratados musicales antiguos para indicar el correcto cálculo y utilización de los sonidos como base para la composición de piezas musicales. No obstante, durante la Edad Media, muchos de los tratados se expresaban con el término 'música', aunque es sabido que el estudio de la misma estaba dedicado a la consecución de respuestas a problemas propios de la 'armonía', en especial, a la inconmensurabilidad de los intervalos armónicos entre sí. La teoría musical renacentista fue heredera de esta problemática y Kepler sería uno más de los que intentaría dar respuesta a dichos problemas. Así entonces, el término 'armonía' se refiere siempre aquí, a la base teórica -geométrica o matemática- de la música. Ahora, respecto al término 'música moderna figurada' se refiere Kepler a las técnicas polifónicas de la época, las cuales, en general, presuponían la superposición de diversas líneas melódicas -hasta seis o más- con un diseño propio y variadas figuras o motivos rítmicos. Dichas líneas se escuchaban simultáneamente y se conducían según las leyes del contrapunto, las cuales describían, a grandes rasgos, los movimientos correctos de las líneas melódicas, unas respecto de las otras, y las consonancias o disonancias permitidas. Para la época de Kepler, las consonancias aceptadas eran los intervalos armónicos de octava, quinta, cuarta, terceras y sextas -mayores y menores-. Las disonancias y el resto de los intervalos se presentaban cada vez con mayor fuerza, dada la variedad de figuras rítmicas que los compositores utilizaban y los efectos expresivos que se quería lograr.

$$
\therefore \therefore
$$

$6 \therefore \because$ El tetractys (lit. el cuarto) es un arreglo triangular de 10 puntos en forma de cuatro filas de uno, dos, tres y cuatro elementos, respectivamente. En la aritmética pitagórica era entendido como el cuarto número triangular después del 1, 3 y 6 y como una representación del número 10. A su vez pertenecía al misticismo simbólico de los pitagóricos, quienes lo asociaban a los cuatro elementos y al orden en el cosmos. 
la "verdad" y, al igual que en las otras disciplinas mencionadas, en la música se ofrecía un cuerpo de leyes debidamente reglamentado. La única diferencia estribaba en que aquella verdad poseía un componente estético y sensible que estaba embebido e indisociado. Como bien apuntaba Aristoxeno:

El geómetra, no se sirve de sus facultades sensibles, no ejercita su vista para juzgar ni bien ni mal la recta, el círculo o cualquier otra figura, siendo esto más bien tarea del carpintero, del tornero o de otros artesanos. Pero para el estudioso de la ciencia musical es fundamental, en cambio, la exactitud de la percepción sensible, porque no es posible que quien tiene una percepción sensible deficiente pueda explicar convenientemente fenómenos que no ha percibido de ningún modo $[\ldots]^{7}$

Como puede deducirse de lo anterior, el juicio musical verdadero era único, pues siempre incorporaba dentro de sí lo bello, no de manera accesoria, sino fundacional. No obstante, hacia el siglo XVIII la música (tanto en sus aspectos teóricos como prácticos) sufrió modificaciones que acabarían por escindirla en dos vertientes claramente diferenciadas: acústica físico-matemática (música como ciencia) y la música propiamente dicha: composición, ejecución y audición (música como arte o lenguaje).

Esta serie de cambios son objeto de estudios recientes, tanto para la musicología como para la historia de la ciencia y, en especial, la llamada Revolución Científica, es requerida hoy para que incluya, definitivamente, a la música como uno de sus aspectos más ilustrativos. ${ }^{8}$ Este es el marco teórico general en el cual se inserta el presente ensayo y, en el caso particular del Harmonices Mundi, interesa, sobremanera, el insistente deseo de su autor por justificar su investigación, en relación con las prácticas musicales del momento: la polifonía, en el paso de los siglos XVI al XVII y la obra de compositores como Orlando di Lasso, y todo lo que hoy se conoce como la polifonía franco-flamenca. Las referencias de Kepler a esta música -tanto en sus libros como en sus cartas- y, en especial, a Lasso, son harto significativas y se intentará demostrar cómo pueden considerarse el disparador de muchas de sus hipótesis filosóficas y científicas. En este sentido, la polifonía del siglo XVII habría revelado, en su belleza y complejidad, la

7 Véase la más reciente traducción completa de los Elementa Harmonica de Aristoxeno en BARKER, 1989. La cita está extraída de la traducción al castellano de TARAZONA, 1994: 93.

8 El término 'Revolución Científica' ha sido, desde la última cuarta parte del siglo XX, objeto de variadas revisiones. Lo que en un primer momento en 1939 -iniciado por el filósofo e historiador de la ciencia Alexander Koyré (*Taganrog, Rusia, 1892; $†$ †arís, 1964) - se convirtió en un tópico de "modernidad", "cambio intelectual radical" o de "ruptura entre lo viejo y lo nuevo", es puesto en tela de juicio a raíz de lo que hoy se sabe de la vida cultural del siglo XVII. Como dice Steven Shapin: "Debido a los cambios que ha experimentado en los últimos años nuestro conocimiento de la ciencia del siglo XVII, los historiadores cada vez consideran con más recelo la idea misma de la «la Revolución Científica». Incluso la legitimidad de cada una de las palabras que constituyen la frase ha sido discutida. Muchos historiadores ya no están satisfechos con la idea de que se pueda considerar un acontecimiento singular y discreto, localizado en el tiempo y en el espacio como «la» Revolución Científica. Ahora, estos historiadores rechazan incluso la noción de que existiera en el siglo XVII una única entidad cultural coherente que pudiera experimentar un cambio revolucionario. Lo que había, más bien, era una diversidad de prácticas culturales que se proponían comprender, explicar y controlar el mundo natural." Véase SHAPIN, 2000. La música, en el marco de la Revolución Científica y la historia de la ciencia, se ha caracterizado por ser una disciplina incómoda tanto para las historiografías tradicionales como para otras más recientes. Sin embargo, ha sido, justamente, esta revisión del término 'La Revolución Científica', la que ha permitido que la música haya recibido una mayor atención por parte de los historiadores de la ciencia. La música ha terminado por ofrecer nuevos puntos de vista de la propia Revolución Científica, tanto de los personajes en ella involucrados como de las disciplinas que con la música confluyen, v.g. la física, la matemática, la astronomía, la alquimia, la magia natural y otras. En resumen, el mencionado término será utilizado aquí tomando en cuenta esta nueva noción que se tiene de él. 
manifestación de los arquetipos del Creador y esto inflamó a Kepler a ubicarlos en las esferas celestes. Es decir, la experiencia estética musical habría precedido a la formulación científica, siendo su acicate y ofreciéndole un marco de verdades manejable y compartido. Tras revisar el tema desde Pitágoras, pasando por Ptolomeo y hasta llegar a su propia época, pudo Kepler relanzarlo con sus aportes propios y originales.

Partiendo del impulso de nuevas traducciones (véase supra Nota 4), el Harmonices Mundi puede ser objeto de una relectura que revise tanto sus aspectos filosóficos como musicales. No es un atrevimiento decir que la actividad editorial digital (en sus aspectos multimedia e interactivos) puede acompañar esta nueva mirada para intentar colocar en un estado más comunicable o digerible, lo que muchos de los estudiosos consideran un libro complejo, abstruso, confuso y difícil de leer. Un lector, por más versado que esté en historia de la ciencia, si no posee un mínimo de conocimientos musicales estará perdido entre fracciones, razones, escalas y modos -sin contar con la notación musical antigua-, que no le permiten comprender en detalle los planteamientos del autor. A su vez, el musicólogo de oído refinado, pero no dado al malabarismo de las fracciones armónicas, puede terminar considerando la obra como puros ardides numerológicos. Si bien Kepler aclaraba en su astronomía que los planetas no producen sonidos, también dejó asentado que coexistían allí una armonía sensible y una abstracta. Por ello, tanto su lenguaje como su corpus racional astronómico, están impregnados de sonido y son, evidentemente, herederos de la música. Una octava o diapason, el monocordio, la noción de polifonía y simultaneidad, los géneros durus y mollis y otros términos utilizados por él, provienen de la teoría y práctica musical y se solapan, interseccionan, y trasladan a la astronomía con naturalidad. Y viceversa.

En resumen, esta compleja mezcla de aritmética, geometría, astronomía y música convierten al texto del Harmonices Mundi en un tour de force multidisciplinario. Con seguridad, es posible -si se hace de manera acertada- desplegar los aspectos visuales y sonoros de esta obra, de una manera explícita y, para ello, en el siguiente enlace: http://www.calderon-online.com/anuariomusical/kepler/, se presenta un intento multimedia que, partiendo de los grabados originales y apegados a los textos del autor, podría considerarse una condensada versión, animada y sonora, de las argumentaciones expuestas por Kepler en su Libro V. Se ruega al lector que consulte este enlace para la correcta y total comprensión de lo aquí expuesto, además del disfrute visual y sonoro de los argumentos keplerianos.

$* * *$

La obra de Kepler y, en especial, los libros del Harmonices Mundi, pueden interpretarse como un amplio y ambicioso intento por fundir en una sola pieza lo que hoy son dominios con técnicas propias y distanciadas entre sí: la geometría (Libros I y II), la música (Libro III), la astrología (Libro IV) y la astronomía (Libro V). La mirada kepleriana las funde y homologa bajo los arquetipos creados por un dios que es, a su vez, diseñador de polígonos, sólidos y figuras (geómetra), instaurador de las razones y proporciones armónicas (músico) y, finalmente, responsable tanto de las variaciones del mundo sublunar (astrólogo) como de los orbes celestes (astrónomo). Como sugiere el propio Kepler, el Harmonices Mundi invita a imitar a Dios (aunque sólo sea por una breve fracción de tiempo), adentrarse en sus planes y sa- 
borear su placer creador. Esta obra se configura así, simultáneamente, en demiurgo y ángel exterminador; puesto que puede verse como uno de los primeros intentos de fundamentar la realidad en la observación y la medida, pero también, como de los últimos intentos de construir una metafísica de los saberes de una época. Puede que algunos intelectuales, golpeados por el "desencantamiento del mundo", desearían que todo lo expuesto por Kepler hubiera sido verdad; otros, menos ingenuos, saben que el encanto no está en la correspondencia de la metafísica kepleriana con la realidad, sino en lo hermoso de sus argumentaciones racionales, aunadas a su imaginación exaltada y su aroma espiritualista. Jano bifronte pues, tanto en el tiempo como en el espacio.

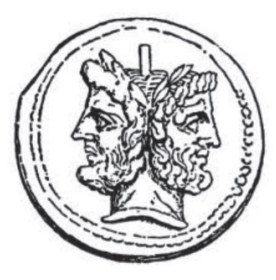

Figura 2. Moneda romana con el perfil del Jano bifronte

\section{EL MARCO GENERAL: LO BELLO, LO FEO Y LO DIGNO DE SER CUANTIFICABLE}

Hay consenso entre filósofos e historiadores de la ciencia en ubicar el descubrimiento de las fracciones armónicas sonoras como la primera ley físico-matemática. Según transmite la tradición divulgada a lo largo de la Edad Media, Pitágoras pudo establecer, después de escuchar por azar los sonidos del golpeteo de unos yunques de diversos pesos y tamaños, una conexión de índole numérica entre la consonancia y el hecho sonoro físico, es decir, entre lo agradable al oído de un hecho físico real y su correspondiente modelo matemático; entre estética y ciencia. Como es fácil notar, ese aspecto estético -o por lo menos, una cierta complacencia desinteresada- estuvo en la base del nacimiento de esta antiquísima ley; no obstante, hoy día, la conexión entre un hecho físico y su modelo matemático explicativo prescinde, en la inmensa mayoría de los casos, de los juicios estéticos del observador. No se quiere negar que tanto el acto de observación como el conocimiento producido le reporten algún goce estético a quien lo realiza, e incluso es sabido que el científico se afana por producir teorías simples y hermosas, pero la conexión que va de la estética a la física, y de ahí a la matemática, no es necesaria. Es decir, no se escucha música o se disfruta el arte plástico para luego formular teorías científicas y, por ello, lo feo, por decirlo así, es, igualmente, matematizable, y no por ello desdeñable como portador de conocimiento. Con seguridad, el fenómeno estético y otras consideraciones en torno al gusto, pueden ser motivo para incitar la investigación (e incluso pueden llegar a ser una guía metodológica) pero es menester reconocer que la ciencia, tal como la conocemos actualmente, dista de tener a la estética como su fundamento principal. Para eso, justamente, 
nació en el siglo XVIII -simultánea a la consolidación de la llamada Revolución Científica- la Estética, como disciplina independiente asociada a las artes y a la filosofía, para explicar en qué consiste lo bello, tanto de la realidad natural como de los productos humanos. Pero la pregunta que se hiciera Pitágoras en los albores del pensamiento filosófico, fue, de hecho, una pregunta estética: ¿Por qué esto es bello? ¿Qué hace que este hecho físico sonoro se presente complaciente y agradable ante nuestros oídos? Y como toda pregunta estética, sigue sin respuesta; a pesar que los pitagóricos obtuvieran la suya en una argumentación matemática: proporciones de números enteros. Lo que interesa destacar es que desde aquél primer momento, fue la experiencia estética la que estimuló a la filosófica, y que el encuentro "música-estéticafísica-matemática-filosofía-ciencia" era susceptible de ser investigado en conjunto.

Las reflexiones filosóficas en torno a la música, el orden y esta noción de belleza gobernada por cánones matemáticos, es una de las líneas de pensamiento que desde el Timeo de Platón, y a lo largo de la historia de la ciencia, llega limpia y repotenciada por personajes como Ptolomeo y Proclo hasta la investigación kepleriana. ${ }^{9} \mathrm{Si}$ alguna ciencia pudo salvar épocas y avatares filosóficos fue la música y, en especial, sus aspectos teóricos: la llamada armonía.$^{10}$ Seguramente, algunos filósofos naturales como Kepler y Fludd -por citar apenas un par- podrían estar en desacuerdo en muchas cosas, pero la fundamentación armónica la consideraban incontrovertible. ${ }^{11}$ Por ello, la música, entendida como ciencia, puede evidenciar, sin duda, aspectos del desarrollo histórico del pensamiento científico; no obstante, cuando un historiador de la ciencia como Thomas Kuhn se tropieza con ella, su reacción es considerarla como una "excepción”. En su libro La Tensión Esencial, al evaluar el desarrollo de las ciencias de la antigua Grecia en el marco de la Revolución Científica y las drásticas transformaciones que sufrieran las llamadas ciencias físicas clásicas, dice Kuhn: "Todas estas ciencias [astronomía, estática, óptica, matemáticas], menos la armonía, fueron reconstruidas desde sus cimientos durante los siglos XVI y XVII." ${ }^{12}$ Y en el mismo párrafo, como nota al pie, nos aclara:

Aunque la armonía no se transformó, su posición declinó mucho de fines del siglo XV a principios del siglo XVIII. Fue siendo relegada cada vez más a la primera sección de tratados dirigidos principalmente a asuntos prácticos: composición, temperamento y construcción de instrumentos. Todos estos temas fueron adquiriendo predominio aun en los tratados completamente teóricos, y de la misma manera la música se fue apartando de las ciencias clásicas. Pero tal separación llegó tarde y nunca fue completa. Kepler, Mersenne y Descartes, todos ellos escribieron sobre armonía, Galileo, Huygens y Newton se mostraron interesados en ella [...] ${ }^{13}$

9 Puede considerarse al diálogo platónico Timeo (360c. a.C.) como una de las referencias escritas más antiguas en la cual, a su vez, pueden evidenciarse las raíces cuasi míticas del encuentro entre cosmogonía, física y antropología, aunada a la armonía y la música. La influencia de este diálogo no decayó a lo largo de la Alta y Baja Edad Media siendo el filósofo y matemático neoplatónico Proclo (*Constantinopla, 410; †Atenas, 485) uno de sus más reconocidos comentaristas. Al respecto del matemático, astrónomo y geógrafo Ptolomeo (*Alto Egipto, 100 c.; †Alejandría, 170 c.), se comentará, más adelante en el Apartado 3.1, su influencia en la obra de Kepler.

10 Véase supra Nota 5 al respecto de los términos 'armonía' y 'música'.

11 Robert Fludd (*Kent, 1574; †Londres, 1637) fue un filósofo y médico con variados intereses como la alquimia, la astrología y la armonía. Sostuvo una controversia con Kepler que lo acusaba de utilizar la armonía de una manera puramente simbólica, a diferencia de él, que la justificaba con rigurosos cálculos numéricos. Véase al respecto, una revisión de dicha controversia en el apartado "Matemático territorial en Linz: Controversia con Robert Fludd", en CASPAR, 2003: 370-374.

12 KUHN, 1977. La cita está extraída de la edición al castellano: KUHN, 1982: 65.

13 Ibid. 
Como puede leerse, Kuhn reconoce la presencia notable de la música en la historia de la ciencia y en la obra de destacados filósofos naturales, pero sin embargo, las transformaciones que sufriera en el siglo XVIII le llevan a "apartarla” de las ciencias clásicas, para concluir que no habría sufrido la reconstrucción de muchas de las otras disciplinas. Finalmente, habría evolucionado, suave y elegantemente, de dos maneras: a) por el lado teórico y científico, derivaría en la física acústica, y b) por su lado práctico y artístico, en las leyes de composición musical. ${ }^{14}$ Estas dos líneas de investigación ya no poseerían, necesariamente, puntos de encuentro, y es tal que, hoy por hoy, el músico práctico puede desconocer las complejidades de la física acústica para la composición de su obra. Y, viceversa, el científico acústico no necesariamente debe conocer las técnicas de armonización de melodías, cadencias y otros aspectos propios del compositor. ${ }^{15}$

Lo que interesa destacar es que para comienzos del siglo XVII esta separación no se ha dado aún y que la llamada Revolución Científica no sólo vivió con intensidad el encuentro entre la especulación matemática y la estética, sino que el estudio de la música y la armonía puede ofrecer un cuadro vívido de la ciencia de ese momento. Lo que para Kuhn es una "excepción”, es, para los interesados en la historia de la música como ciencia, el caso modélico. En este orden de ideas han discurrido la mayoría de los estudios que han vindicado a la música como ciencia, lo cual permite afirmar que hacer historia de la actividad musical acontecida hasta el siglo XVII, es hacer, también, historia de la ciencia.

\subsection{La excepción dentro de la excepción: el Harmonices Mundi}

Aunque la música ya pertenezca al grupo de categorías conceptuales que, actualmente, manejan los historiadores de la ciencia, el encontrar partituras musicales en un libro sobre la ciencia del siglo XVII, es muy poco frecuente. Entre las notables excepciones está el Harmonices Mundi de Johannes Kepler. Casi toda referencia a esta obra paga el "peaje musical" de colocar el grupo de pentagramas que, a manera de cantinela, éste asignó a las órbitas planetarias. Se habla de la siguiente figura:

14 El ejemplo canónico de "leyes musicales", en este nuevo sentido, es la teoría armónica de Jean Philippe Rameau (*Dijon, 1683; †París, 1764), compositor, clavecinista y teórico musical que algunos llamarían el Newton de la música. Su tratado teórico sobre la armonía, entendida ahora como las leyes de los encadenamientos de acordes y la composición musical, es RAMEAU, 1722. (Pueden verse las ediciones digitalizadas del original en francés junto a dos ediciones en inglés de 1775 y 1779), en el enlace dedicado a Rameau: http://imslp.org/wiki/Category:Rameau, Jean-Philippe (Revisado el 07-09-2012).

15 Claro está, siempre y cuando la obra no se refiera a una investigación estética de índole acústica o electroacústica propiamente. Lo que no es menos cierto es que los conservatorios de música de la mayoría de los países prescinden, en su formación básica, de asignaturas como "física" o "acústica" e, igualmente, no se enseña "música" a los ingenieros, físicos o matemáticos universitarios. 


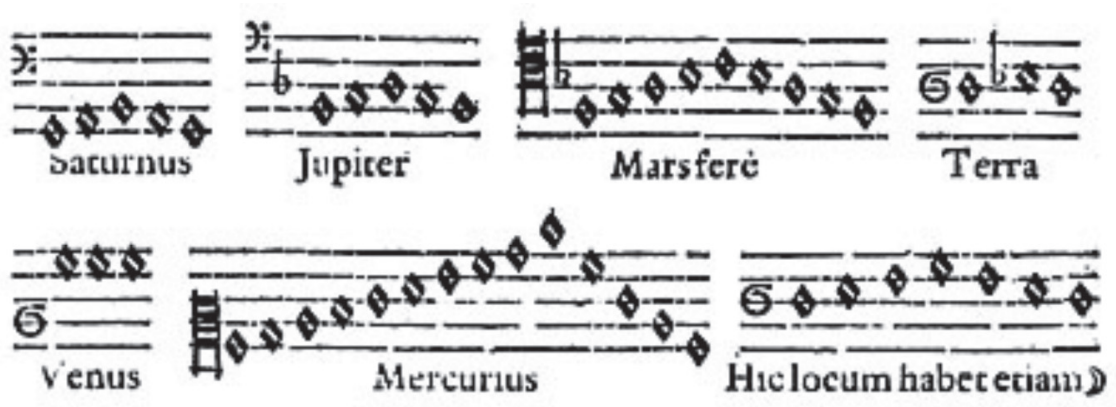

Figura 3. Melodías y modos asociados a los planetas individuales y a la Luna, tal como está expuesto en el Libro V. KEPLER, 1619, V: 207

Hasta bien avanzado el siglo XX -1985- algunos historiadores de la ciencia y biógrafos consideraban esta obra como una suerte de "lujuriante fronda de fantasía", ${ }^{16}$ impregnada de música, magia, esoterismo y misticismo de donde podía extraerse la casi oculta Tercera Ley Planetaria y entregarla a un desagradecido Newton para que éste enunciara su Ley de Gravitación. ${ }^{17}$ No obstante, ya desde 1948, Max Caspar, en la que es considerada la mejor de las biografías de Kepler, venía clamando por una visión ponderada de la obra diciendo que:

Quien desee conocer toda la magnificencia de esta flor singular deberá enfrentarse a la obra por sí solo. La mayoría de las biografías reproduce el contenido de este libro con gran insuficiencia debido al desconocimiento de sus autores o su incapacidad para valorarlo, y, de hecho, se alude a la tercera ley sin desmenuzar el contexto conceptual en que aparece dentro de la obra. Es decir extraen la perla de su engaste, cuando no hay duda de que solo dentro de él adquiere todo su valor. Pero el estilo de ese engaste no encaja con la objetividad de nuestro tiempo: está colmado de ornamentos evocadores cuya belleza simbólica bloquea a muchos. ${ }^{18}$

Este bloqueo fue finalmente roto cuando musicólogos como Daniel. P. Walker o Michael Dickreiter pudieron exponer con diferentes énfasis los detalles musicales e intentaron explicitar esta mencionada "belleza simbólica". ${ }^{19}$ Mientras algunos historiadores de la ciencia insistían en el "sonambulismo" de Kepler -v.g. Koestler en su libro The sleepwalkers, véase Nota 16-, Walker abordaría mas bien, en su ensayo "Kepler's celestial music", la gran mayoría de los aspectos musicológicos para terminar precisando, cinco

16 KOESTLER, 1959. La cita está extraída de la versión al castellano: KOESTLER, 1985: 141.

17 Como es bien sabido por los historiadores de la ciencia, la Tercera Ley Planetaria de Kepler enuncia que, para cualquiera de los planetas, hay, siempre, una proporción constante al relacionar la distancia promedio al sol con el tiempo de una revolución a su alrededor. Esto puede enunciarse de la siguiente manera: $K=T^{2} / R^{3}$, siendo $K=$ constante, $T=$ período, en unidades de tiempo y $\mathrm{R}=$ radio orbital medio, en unidades de distancia. A pesar que Newton utilizó las leyes de Kepler para la derivación y formulación de su Ley de Gravitación Universal, no hizo mención explícita a Kepler. A este respecto véase la "Introducción” de Eloy Rada a la edición en castellano de NEWTON, 1987: 38.

18 CASPAR, 2003: 368. [Énfasis añadido]

19 WALKER, 1979: 34-62. DICKREITER, 1973. 
aspectos bien diferenciados en su armonía y música: a) es realmente silenciosa y no se oye, ni siquiera para los oídos pitagóricos, b) es polifónica y no sólo compuesta de escalas individuales, c) se fundamenta en la geometría y en la especulación numérica, d) es heliocéntrica, se percibe desde el Sol y no desde la Tierra, c) está basada en la llamada "afinación justa" que incluye también como consonancias las 3ras. y 6tas. mayores y menores, de proporción 4:5; 5:6; y 3:5; 5:8, respectivamente, y que fuera sistematizada por Gioseffo Zarlino. ${ }^{20}$

Walker mostró las analogías establecidas entre la música y los cielos e insistió en que no debían ser consideradas tan solo metáforas de la imaginación kepleriana. Otros aspectos como la entonación justa, la polifonía, así como la referencia a músicos como Orlando di Lasso eran brevemente mencionados como elementos fundamentales para comprender la obra. El análisis de Walker merece ampliarse en la medida que se intente interconectar, con más fuerza, las conclusiones musicológicas con las argumentaciones astronómicas, además de exponer el contexto histórico y musical desde donde Kepler realiza sus argumentaciones. Esto permitiría presentar algunas evidencias para responder preguntas como: ¿Por qué para Kepler la polifonía contemporánea es un elemento de tanto peso en sus argumentaciones astronómicas? ¿Por qué insiste en diferenciar la "música moderna figurada" de aquella de los "antiguos”? ¿Qué papel desempeña la música de Orlando di Lasso en esas argumentaciones? ¿Qué relación tienen esas argumentaciones con el gusto musical de la época y el de las cortes alemanas?

En el caso de Michael Dickreiter, su libro Der Musiktheoritiker Johannes Kepler, es un compendio de casi todo lo que tenga que ver con la actividad musical kepleriana. Este libro es una investigación que gira íntegra sobre la esfera musical y como tal es una mirada totalmente distinta del Kepler astrónomo o astrólogo: es el Kepler músico. En el capítulo central de la Primera Parte, Dickreiter justifica esta mirada musical del astrónomo, con base en la naturalidad que para Kepler, y la mayoría de los tratadistas del barroco musical alemán (como por ej. Andreas Werckmeister), era considerar la especulación armónica como una disciplina ligada a unas matemáticas en sentido amplio. ${ }^{21}$

A lo anterior hay que añadir que este barroco germano, heredero de la Reforma luterana, fue un período cuya producción en artes plásticas, en comparación con las grandiosas empresas contrarrefor-

20 Queda claro que una proporción del tipo $m: n$, con $m>n$, al expresarse en la forma $n: m$ se considera una inversión y para efectos de la armonía tradicional, puede considerarse equivalente y así, por ejemplo, la proporción 2:1 y 1:2 se refieren, siempre, a la octava. En esta investigación, se ha optado por colocar las proporciones en la forma $n: m$ (con $n<m$ ), dado que en la obra de Kepler, por lo general, así son utilizadas. Gioseffo Zarlino (*Chioggia, 1517; †Venezia, 1590), como es bien sabido por los musicólogos, fue un compositor y teórico musical cuya obra se considera fundamental en el Renacimiento italiano. Zarlino ofreció un razonamiento sistemático a las proporciones armónicas de la llamada "afinación justa", la cual incorporaba nuevas terceras y sextas. Basado en las propiedades numerológicas del "6" (el número senario) Zarlino demostró que el esquema de consonancias pitagóricas basadas en el tetractys (véase supra Nota 6) podía expandirse incorporando consonancias que provenían de utilizar el senario, es decir, las proporciones 4:5, 5:6 y sus derivadas $3: 5$ y 5:8, para las terceras y sextas -mayores y menores-, respectivamente. La obra que recoge esta sistematización es: ZARLINO, 1558. Pueden verse las ediciones de 1558 y 1589 , transcritas e indexadas electrónicamente, en http://euromusicology.zoo.cs.uu.nl/dynaweb/tmiweb/z/, enlace perteneciente al Thesaurum Musicarum Italicarum. También pueden consultarse ediciones digitalizadas facsímil, en el enlace de la Biblioteca Digital Europeana. http://www.europeana.eu/portal/search.html?query=zarlino, (Revisado el 07-09-2012).

21 CASPAR, 2003: 175-176. Puede verse la traducción al inglés de este único capítulo titulado "The structure of harmony in Johannes Kepler's Harmonices Mundi”, en GOZZA, 2000: 173-188. Andreas Werkmeister (*Benneckenstein, 1645; †Halberstadt, 1706) fue un músico y teórico alemán conocido, actualmente, por sus sistemas de afinación y su relación con el término "buen temperamento", el cual Johann Sebastian Bach utilizara para la composición de su obra Das Wohltemperierte Clavier en 1722. 
mistas católicas, fue limitada. No obstante, el propio Lutero se encargó de convertir a la música en la punta de lanza de su proyecto religioso y, a través del canto sencillo de sus corales cuidadosamente cultivados, pudo expresarse hasta llegar a considerar que, dejando de lado la Teología, no había arte alguno que pudiera ponerse a la misma altura que la música. ${ }^{22}$ Así pues, la vocación musical de Lutero puede considerarse un legado cultural valioso para los pueblos germanos, y a principios del siglo XVII esa herencia abarcaba desde el pueblo llano hasta los filósofos naturales como Kepler: un luterano cabal. Debe quedar claro que la actividad musical kepleriana -aunada a la matemática- no debe verse tan sólo como un elemento más de su formación o personalidad, sino que forma parte integral de una visión del mundo que persiste en la historia e, incluso, llega hasta la actualidad pues, mientras en la mayoría de las iglesias protestantes de hoy, sus fieles toman la Biblia, ubican los salmos y cantan leyendo la partitura, la iglesia católica aún deja eso a los músicos o cantantes profesionales o, en todo caso, al oído natural de la feligresía, sea educado o no.

\section{EXPERIENCIA ESTÉTICA Y FORMULACIÓN CIENTÍFICA}

Para apreciar el impacto que pudo haber tenido la música en la obra de un filósofo natural como Johannes Kepler es necesario que distingamos aquí la simple fruición, de la experiencia estética que opera en la persona cultivada en un particular arte. En el caso específico de Kepler, sus juicios estéticos musicales no son simples discursos productos de su sensibilidad, sino juicios amparados en una sólida formación musical que hinca sus raíces en su temprana juventud (monástica y teológica) y en el continuo reflexionar acerca de la música a lo largo de su vida. Si se hace un breve recorrido por su "vida musical" pueden establecerse relaciones con el contexto más amplio del ámbito musical europeo de los siglos XVI y XVII. En este sentido, la lectura de un tratado como el Harmonices Mundi debe estar igualmente orientada por varios vectores, es decir, debe ser a la vez numérica, sonora y piadosa. Sirva este ensayo para las dos primeras, ya que los misterios de la tercera pueden intuirse, mas se nos escapan.

22 Las cartas de Lutero poseen abundantes referencias a la música como don divino y su papel fundamental en la cultura y la formación individual. La edición completa de dichas cartas es: LUTERO, 1959. Al respecto de la relación de Lutero y la música véase: BUSZIN, 32,1(Oxford, 1946): 80-97. Véase también el capítulo "Luther on Music: A Theological Basis for German Baroque Music", en BARTEL, 1997: 3-9. 


\subsection{La formación musical de Kepler}

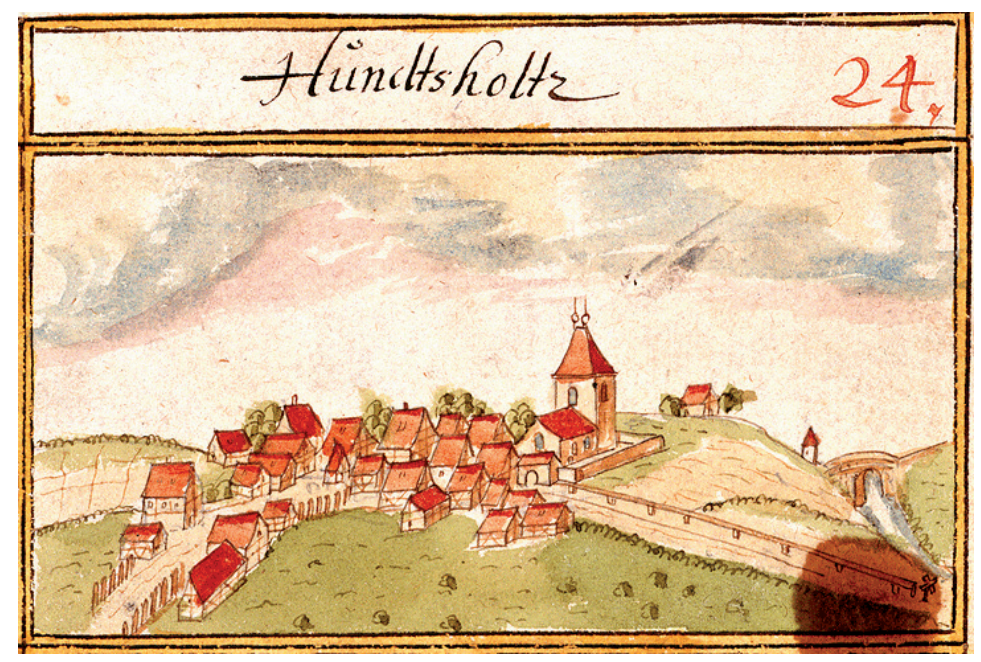

Figura 4. Villa de Hundsholz (hacia 1685), lugar donde funcionó la escuela monástica de Adelberg hasta 1648. Dibujo por Andreas Kieser (*Frankfurt, 1618; †?, 1688)

Los salmos de la niñez. Kepler comenzó su formación musical a partir de que fuera aceptado en 1584, a la edad de 13 años, en la escuela monástica de Adelberg. Conforme se preparaba a los niños para sus futuros estudios de Teología, el plan los instruía con cantos colectivos e himnos sagrados en contrapunto figurado. Además,

Täglich 9 Uhr "Exercitium Chori” und samstags zwischen 14 und 15 Uhr Musiktheorie "secundum praecepta Nicolai Listenii", ${ }^{23}$

Esta rutina, repetida durante seis años durante su estancia en las escuelas monásticas de Adelberg y Maulbronn, con seguridad, otorgó a Kepler una formación musical imborrable. Las siete canciones eclesiásticas y los himnos que respectivamente mencionara, más tarde, en su Harmonices Mundi, provienen

23 "Diariamente, a la Hora 9, Ejercicio Coral y los sábados entre las 14 y las 15, Teoría Musical según los preceptos de Nicolaus Listenius". Véase este programa de estudios en DICKREITER, 1973: 124. Nicolaus Listenius (*Hamburgo, 1510; †?), fue un músico y teórico que escribió en 1533, textos orientados a la formación de jóvenes en los rudimentos de la música, entre ellos destaca: LISTENIUS, 1533. Esta obra recibió, hasta 1583, innumerables ediciones y se caracterizaba por la enseñanza del canto a partir de sencillas reglas y ejemplos musicales. Pueden verse las ediciones de los años 1535 y 1538 en el enlace http://imslp.org/ wiki/Rudimenta musicae (Listenius, Nicolaus). (Revisado el 07-09-2012). Esta obra también destaca por ser la primera donde se incorporaba, a los tradicionales términos musica theorica y musica practica, el término poética; como aquello que, una vez escrito y culminado, queda como doctrina o instrucción. Este término, posteriormente en el siglo XVII, sería utilizado para establecer un sistema de "figuras retóricas musicales" con objetivos similares a la retórica del lenguaje. 
del repertorio diario de sus estudios de canto. ${ }^{24}$ Sus estudios musicales continuaron y se intensificaron en la Universidad de Tübingen donde obtuvo en 1591 su título de Magister Artium (Maestro en Artes). ${ }^{25}$ Durante este período el maestro de música de la Facultad de Artes daba lecciones los jueves, sábados y domingos; en horas libres y en vacaciones. Tres años después, cuando Kepler finalizara sus relaciones con la universidad, es lógico pensar que hubiera construido un conocimiento sólido sobre la ciencia armónica, la cual estaría a su disposición para la especulación filosófica durante su siguiente estancia en la ciudad austríaca de Graz.

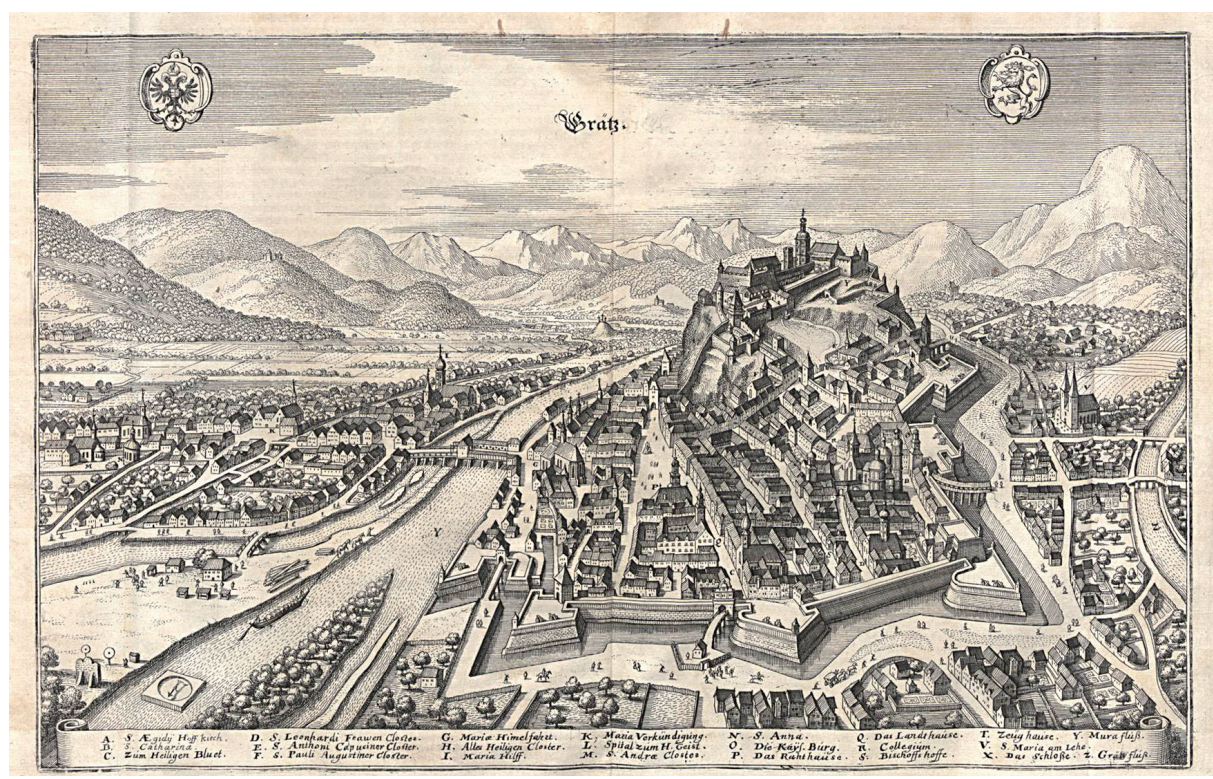

Figura 5. Graz (hacia 1600).

Grabado por Mathäus Merian (*Basilea,1593 †Wiesbaden, 1650)

La actividad musical en Graz. En 1594 Kepler se trasladó a Graz y aceptó el puesto de maestro de matemáticas. En esa ciudad, la actividad musical era igualmente intensa y la corte del archiduque habsburgués Carlos II y su sucesor Fernando, mantuvieron estrecho contacto con músicos italianos, especialmente venecianos. ${ }^{26}$ Asimismo, la corte se nutría de piezas musicales en donde destacaban obras de Phillippe de Monte (futuro kapellmesiter de Rodolfo II en Praga) y de Orlando di Lasso, quien ya había

24 Cfr. KEPLER, 1619, III: 72-73, con el capítulo “De Tonis”, en LISTENIUS, 1533.

25 Este título se obtenía después de dos años de estudios y era necesario para luego poder optar a los estudios de Teología.

26 Entre estos músicos venecianos destacaron el célebre compositor y organista Andrea Gabrielli (*Venecia, h.1510; †Venecia, 1586) junto a su alumno, el tratadista musical Ludovico Zacconi (*Pesaro, 1555; †Fiorenzuola di Focara, 1627) y también Annibale Padovano (*Padua, 1527; †Graz, 1575) quien fuera organista en la catedral de San Marcos en Venecia y luego maestro de capilla del archiduque Carlos II en Graz. 
recibido la protección por parte de la familia de María de Baviera, esposa del archiduque Carlos II. ${ }^{27}$ No se sabe si Kepler cantó, interpretó o ejerció, activamente, alguna práctica musical precisa y aunque, por lo menos, sí se sabe que una vez a la semana el coro ensayaba los domingos para el servicio de la misa en la iglesia, sus cartas no hablan de su participación en el mismo. Se sabe que su casa quedaba justo enfrente del castillo de Graz, donde vivía el archiduque y donde se llevaban a cabo las presentaciones de los músicos venecianos. Igualmente, hay evidencias de que en la corte eran bien recibidos sus descubrimientos científicos y que tenía trato con alguno de los funcionarios de la corte; pero eso tampoco permite deducir o verificar si llegó a asistir o no a determinadas ejecuciones musicales o si trabara amistad o discusión con músicos de la corte. Lo cierto es que se encuentran en sus cartas de este período referencias musicales abundantes, a saber: a la teoría musical, a la importancia e influencia de la música italiana, a músicos célebres como Orlando di Lasso, a instrumentos musicales como el clavicordio y a problemas musicales como la afinación y el temperamento. A este respecto Kepler escribió, explícitamente su deseo:

Velim tamen ex aliquo excellenti Musico quibus abundat Italia, discere artificiosam et Geometricam tensionem totius clavichordij, aut si solo aurium judicio feruntur... ${ }^{28}$

Dos días más tarde, escribió otra carta clamando por una explicación sobre la correcta manera de afinar un clavicordio, que, seguramente

\section{[...] didicissem vel quaesivissem ex Orlando, si viveret, $[\ldots]^{29}$}

De estas breves citas podría deducirse -aunque no se tenga evidencia directa- que en algún momento de su vida pudo haber charlado o haber aprendido algo de Lasso, pero, en todo caso, si se reconoce el carácter tozudo y obstinado, aunado al afán de precisión que gobernaba el quehacer kepleriano, este pequeño párrafo da idea de la grandeza y estima que tendría Kepler sobre Lasso, toda vez que lo considerara capaz de responder a sus -seguramente- quisquillosas preguntas.

27 Philippe de Monte (*Malinas, Flandes, 1521; †Praga, 1603) fue un prolífico compositor, siempre en la órbita de la corte de los Habsburgo. Trabajó en Viena y Praga, siendo kapellmeister de Maximiliano II en 1568 y de Rodolfo II en 1594, sucediendo a Orlando di Lasso, a su muerte en 1593.

28 "Pero me gustaría aprender, de alguno de los abundantes y excelentes músicos italianos, a afinar artificiosa y geométricamente todo un clavicordio, y saber si sólo se dejan llevar por juicio del oído.” Carta de Kepler a Edmund Bruce del 18 de julio de 1599. KEPLER, 1937, vol. 14: 13. Poco se conoce sobre el viajero inglés Edmund Bruce, salvo que en virtud de su nombramiento como consiliarus (representante de los estudiantes ingleses entre 1588 y 1594) viajó por Italia y luego vivió en Florencia hacia 1602 y en Padua hacia 1603. Bruce -interesado en las matemáticas, astronomía, botánica y cuestiones militares, tal como se deduce de sus cartas- mantuvo correspondencia con Kepler entre 1599 y 1605 en torno a la redacción del Harmonices Mundi, así como también al respecto de las investigaciones que llevaba a cabo Galileo Galilei. Perteneció al círculo de amigos y eruditos de Gian Vincenzo Pinelli (*Nápoles, 1535 ; †Padua, 1601) quien fuera reconocido por su vasta biblioteca y, justamente, por su papel como mentor del propio Galileo Galilei.

29 "“...] lo aprendería o se lo preguntaría a Orlando [di Lasso], si viviese, [...]”. Carta de Kepler a su amigo Herwart von Hohenburg del 20 de julio de 1599. KEPLER, 1937, vol. 14: 29. Herwart von Hohenburg (*Ausburgo, 1553; Munich, $† 1622$ ) fue canciller de Baviera y un erudito distinguido. Sus intereses eran muy variados e incluían: astronomía, cronología, matemáticas, egiptología y lenguas antiguas. Dado su prestigio y contacto con los intelectuales europeos de la época, von Hohenburg devino en un centro de intercambio epistolar en los cuales participó Kepler. Hacia 1597 se convirtió en su amigo y protector y, continuamente, le enviaba libros y lo estimulaba a la investigación, a través de preguntas que Kepler respondía encarecidamente. 


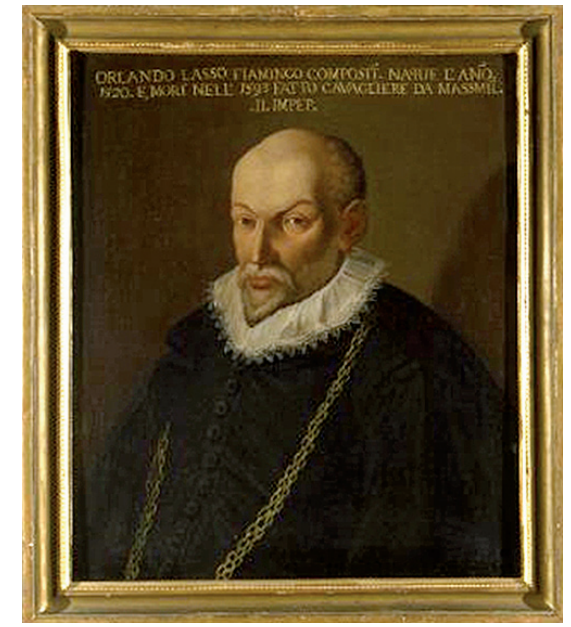

Figura 6. Orlando di Lasso (*Mons, 1530?; †Munich, 1594). Retrato anónimo (hacia 1593), en el Museo Internazionale e Biblioteca della Musica (Bologna)

Orlando di Lasso. La primera mención escrita de Kepler a este músico se encuentra en una carta dirigida a Edmund Bruce de julio de $1599 .{ }^{30}$ En ella hace referencia al motete In me transierunt como ejemplo de la utilización que hace Lasso de armonías con proporción 5:8 (sexta menor) en sus melodías. ${ }^{31}$

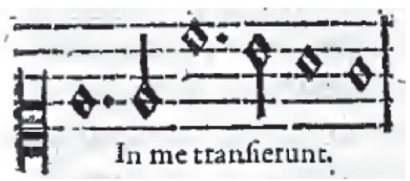

Figura 7. Motivo inicial del motete In me transierunt tal como está expuesto en el Harmonices Mundi. KEPLER, 1619, III: 64

30 KEPLER, 1937, vol. 14: 13.

31 El motete In me transierunt (Me ha trascendido) se cita, por primera vez en el Harmonices Mundi, como ejemplo de excepción -"rarius admictimus"- de intervalo de sexta menor consonante. KEPLER, 1619, III: 64; 1937, vol. 6: 161; 1997: 221. Este motete a cinco voces pertenecía a la edición: Sacrae cantiones quinque vocum. Nuremberg, J. Montanus y U. Neuber, 1562 (RISM 1562a). Los otros dos motetes de Lasso citados por Kepler son Ubi est Abel (¿Dónde está Abel?) y Tristis est anima mea (Mi alma está triste) como, también, ejemplos del delectum -deleite- que ofrecían las consonancias, entre ellas, la sexta menor. KEPLER, 1619, III: 84; 1937, vol. 6: 184; 1997: 253. El primero pertenecía a la edición Primo libro de gli eterni motetti di Orlando di Lasso, Cipriano Rore et d'altri eccel. musici. Venecia, G. Scotto, 1567 (RISM 1567³); el segundo fue publicado, por primera vez, en la antología titulada Modulorum secundum volumen. Paris, Adrian le Roy \& Robert Ballard, 1565 (RISM 1565a). Puede escucharse una versión de referencia de los motetes, en el siguiente enlace http://www.calderon-online.com/anuariomusical/kepler/motetes. 
Que Kepler tome como elemento de referencia musical a Orlando di Lasso, reafirma las cotas de "superestrella" que éste había alcanzado en las cortes alemanas de la segunda mitad del siglo XVI. Este prestigio y reputación internacional lo poseía ya a los treinta años, cuando mereció su primera biografía como "héroe y varón ilustre." ${ }^{32}$ Según esta biografía se cuenta que Lasso había nacido en el año de 1530, en Berga (actualmente, Mons en la región del Hainaut en Bélgica), y fue reconocido ya desde niño por su especialísima voz que podía escucharse en el coro de su ciudad natal. También se narran las tres ocasiones en que el niño Lasso fue "raptado" por personas que, dada su excelente voz, pretendían colocarlo y darle algún empleo. ${ }^{33}$ A los 21 años ya había recorrido los Países Bajos, París, Mantua, Sicilia, Milán, Nápoles y Roma, centros de intensa actividad musical para finalmente, establecerse en Amberes en 1555 como el músico más solicitado de las cortes europeas, tanto por su obra como por su personalidad. A diferencia de Kepler, que poseía un carácter taciturno y melancólico, Lasso era reconocido por su vivacidad, encanto personal, sus dichos, bromas y su pericia políglota. Su obra polifónica moderna, plena de invención melódica y con un carácter más profano atrajo la inquietud del duque Alberto V de Baviera, que era un singular amante de la música. En resumen, la música de Lasso se convertiría en una novedad para los oídos alemanes, y por supuesto, para los de Kepler, acostumbrados a la sencillez de los corales luteranos y obras conservadoras como las de Ludwig Senfl -admirado músico de Lutero- y del kapellmesiter Ludwig Daser. ${ }^{34}$ Para la fecha en que Lasso muere, 1594, Kepler acababa de establecerse en Graz y las referencias musicales que éste hacía del músico, pueden interpretarse como la cota más alta de originalidad y belleza que circulaba en el ambiente intelectual y estético de las cortes que el filósofo frecuentaba.

\subsection{Praga y la Corte de Rodolfo II}

Hay suficientes indicios de la pasión de Rodolfo II por la música y sus deseos por recompensar adecuadamente a los numerosos músicos de su capilla real y su orquesta. ${ }^{35}$ Tanto compositores como

32 Esto se deduce de la biografía escrita en latín “Orlandus de Lassus Musicus” por Samuel van Quickelberg (*Amberes, 1529; †Munich, 1567, médico y humanista empleado en la corte de Múnich desde 1553 hasta 1567) en el compendio de biografías: PANTALEON, 1565.

33 Otros relatos aluden al "rapto" de Lasso, por parte del condottiero Ferrante Gonzaga, cuando el niño músico contaba con la edad de doce años, es decir, el año 1544, fecha en la cual Gonzaga llegó a los Países Bajos. Ferrante Gonzaga (*Mantua, 1507?; $†$ Bruselas, 1557) fue un militar italiano que sirvió al ejército imperial español. Fue virrey de Sicilia (1535), lugarteniente general de Lombardía y gobernador de Milán (1546-1555).

34 Ludwig Senfl (*Zurich o Basilea, 1486?; †Múnich, 1543?) perteneció, en 1496, al coro de niños de la corte de Maximiliano I en Múnich y después fue compositor de la corte hacia 1517. Admirador de la Reforma, estuvo en contacto con Lutero para quien compuso varios motetes. Su música es considerada, formalmente, como la cima de la música medieval alemana y el comienzo de los nuevos estilos asociados a la Reforma. Ludwig Daser (*Múnich, 1525?; †Stuttgart, 1589) fue kapellmeister de la misma corte de Múnich en 1552 y, después de ser licenciado de su puesto tras la llegada de Lasso, tomó un puesto similar en Stuttgart. Su obra incluye, en su mayoría, música sacra y, dada su insistencia en el uso de cuatro voces y técnicas de cantus firmus, es considerada, estilísticamente, conservadora.

35 Rodolfo II de Habsburgo (*Viena, 1552; †Praga, 1612). Emperador del Sacro Imperio Romano Germánico desde 1576 hasta 1612, además de Rey de Hungría y Croacia (como Rodolfo I, 1572-1608), Rey de Bohemia (1575-1608/1611) y Archiduque de Austria (1576-1608). Su legado cultural se caracterizó, en particular, por incorporar a la corte ilustres personajes que 

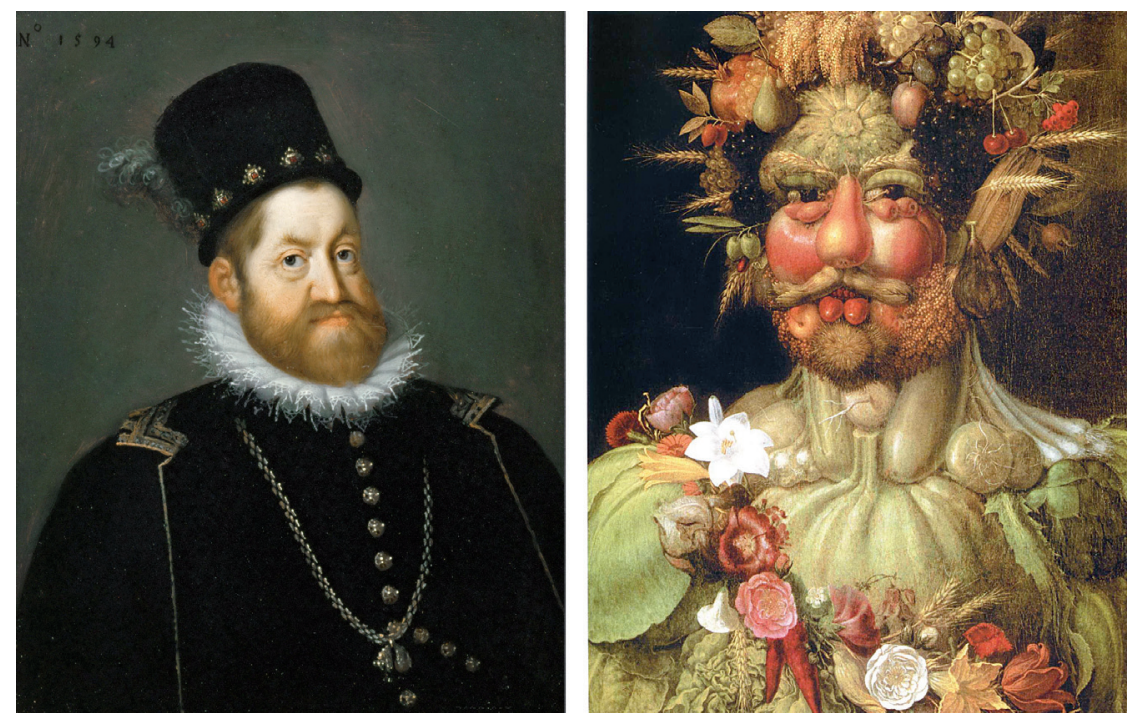

Figura 8. A la izquierda, Retrato del Emperador Rodolfo II (hacia 1592) por Joseph Heintz el Viejo (*Basilea, 1564; †Praga, 1609), en la Galería de Pintura del Museo de Historia del Arte en Viena. A la derecha, Vertumno (hacia 1590; Rodolfo II como divinidad romana de las estaciones) por Giuseppe Arcimboldo (*Milán, 1527; †Milán, 1593) en el Castillo Skoklosters, Suecia

teóricos, cantantes, instrumentistas de cámara y organistas, entraron en camaradería y también rivalizaron entre ellos, pero lo importante a señalar es que esta actividad de la corte se entremezcló con otros intereses intelectuales como la astronomía, la astrología y, conforme el carácter de Rodolfo II se volvió más introvertido y huidizo, acabó por fundirse con la alquimia y el misticismo. En especial, las ratios pitagóricas y toda la especulación armónica formaron un corpus teórico que causó fascinación, además de otorgársele una gran capacidad explicativa, para, finalmente, convertirse en un modelo comprensible de los fundamentos últimos de la realidad.

Este período de Kepler en Praga -de 1600 hasta 1612- es considerado como el más fecundo y, a través de sus cartas, se detecta el entusiasmo creciente por los temas armónicos. Justamente, el año de su llegada a Praga -1600 - se incorporó también a la corte Michael Maier, quien concibió su excéntrico tratado, Atalanta Fugiens (Atalanta fugitiva) publicado en 1618, tres años antes que el Harmonices Mundi. ${ }^{36}$

combinaban saberes arcanos, medievalismos y la filosofía natural propia de la época. Además, su colección de manuscritos, libros y objetos de especial rareza conformaron una de las más célebres wunderkammer (gabinete de maravillas) de la Europa del siglo XVII. Una revisión de estos aspectos puede verse en "Music and patronage at the Court of Rudolf II", en LINDELL, 1994. Lindell indica la existencia, en la corte de Rodolfo II, de cuarenta y cuatro cantantes, cinco músicos de cámara, veintiséis ejecutantes de trompetas y un tamborilero. Ibid.: 269.

36 Michael Maier (*1568, Rendsburg; $† 1622$, Magdeburg), fue, además de filósofo, alquimista y compositor, el médico particular de Rodolfo II y uno de sus más cercanos consejeros. Su obra más famosa es el Atalanta Fugiens: MAIER, 1617. Este 


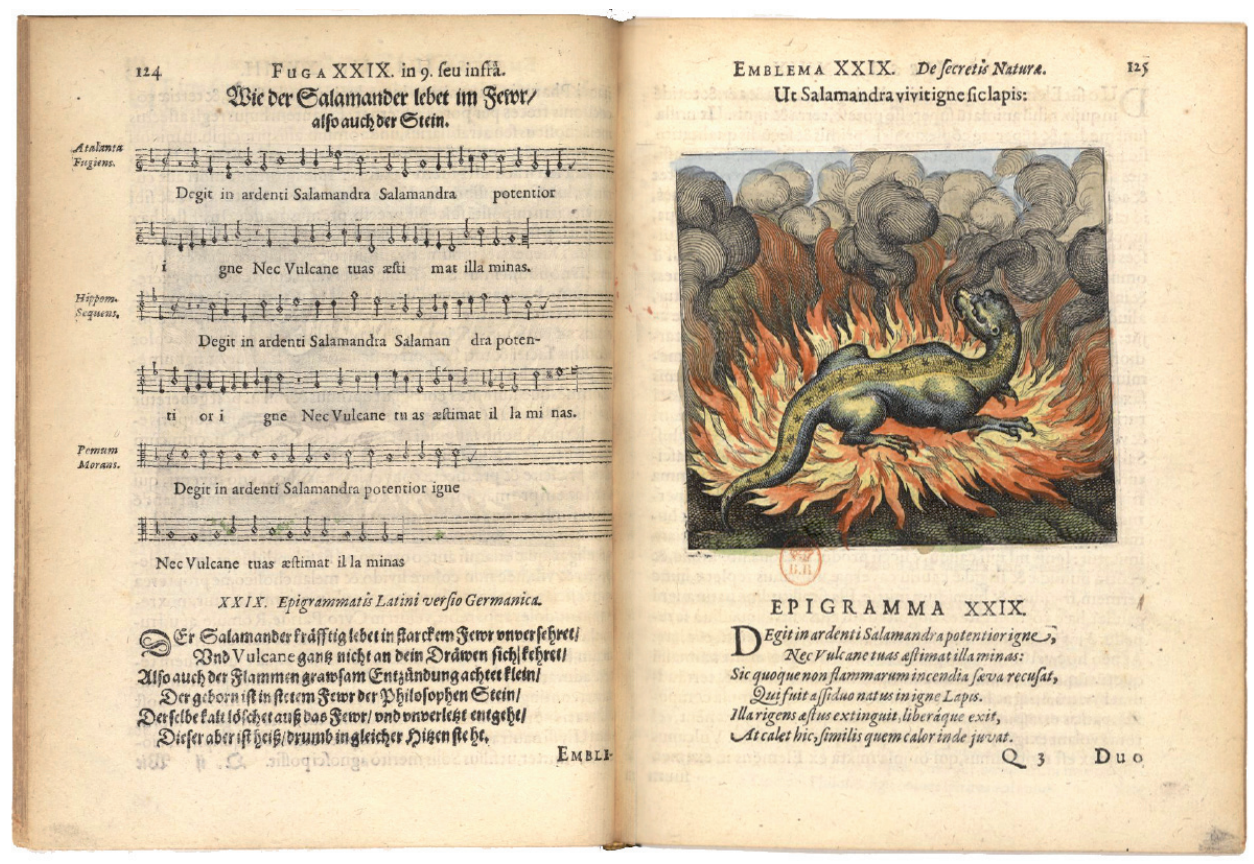

Figura 9. Fuga y Emblema XXIX “Degit in Ardenti” del Atalanta Fugiens. MAIER, 1617: 124-125. ${ }^{37}$

Por otro lado, el pintor favorito de Rodolfo II, Giussepe Arcimboldo (véase Figura 8) ya había mostrado también su interés por fundamentar la pintura, tanto armónica como matemáticamente. Gregorio Comanini, amigo del pintor, lo confirmó en su célebre diálogo Il Figino, donde el personaje principal, -Ambroggio Figino, una suerte de alter ego de Arcimboldo-, decía lo siguiente:

Ma nondimeno così la pittura s'accosta alla musica, come per aventura la poesia fa. Del che io voglio che ve ne faccia prova il da me rammemorato Arcimboldo, il quale ha trovato i tuoni e i semituoni e ' 1 diatesseron e 'l diapente e 'l diapason e tutte l'altre musicali consonanze dentro i colori, con quell' arte apunto che Pitagora inventò le medesime proporzioni armoniche. ${ }^{38}$

tratado se considera como uno de los últimos y más completos intentos por interconectar la alquimia y la música. A través de cincuenta emblemas gráficos, acompañados de un epigrama, un discurso y una fuga a tres voces, su autor insiste en fundir en una sola pieza el oído, la vista y el intelecto. Hay edición al castellano: MAIER, 2007. El tratado puede descargarse desde el enlace http:// gallica.bnf.fr/ark:/12148/bpt6k850551g de la Biblioteca Digital Gallica de la Bibliothèque nationale de France (BnF).

37 Esta fuga, su emblema y su epigrama, pueden leerse y escucharse (al igual que el resto, en el mismo canal de vídeos) en http://www.youtube.com/watch?v=FP5EMCo4UQ4. También, en el enlace http://www.kunstderfuge.com/maier.htm, pueden descargarse las versiones en formato midi de las mencionadas fugas (Revisado el 07-09-2012).

38 "Sin duda, la pintura se aproxima a la música al igual que, a veces, lo hace la poesía. A este respecto quiero ofrecer a Arcimboldo como prueba. Él ha descubierto tonos y semitonos; diatessaron [4ta., 3:4] y diapente [5ta., 2:3] y el diapason [8va., 
La técnica para producir estos intervalos "pictóricos" consistía en tomar como base el blanco y oscurecerlo gradualmente con negro. De acuerdo a las proporciones de blanco o negro, Arcimboldo produjo una escala de grises que hacía corresponder el sonido grave con el color blanco y, conforme lo oscurecía, este crecía en altura hasta alcanzar el sonido más agudo, un negro absoluto. ${ }^{39}$ Según Comanini, Arcimboldo produjo la octava, proporción 1:2, al mezclar una parte de blanco con dos partes de negro lo cual, evidentemente, produce un gris medio oscuro. Si a esa mezcla que ahora se considera como dos partes, se añade una parte de negro adicional, se obtiene la octava superior; y así, consecutivamente, elevando el "sonido-color" y oscureciendo la mezcla. Lo mismo hizo para producir los intervalos del diatessaron 3:4 (cuarta justa) y el diapente 2:3 (quinta justa), agregando en la misma proporción el negro al blanco. En la figura se muestra una interpretación de los porcentajes de negro sobre blanco a los que corresponderían dichas proporciones.

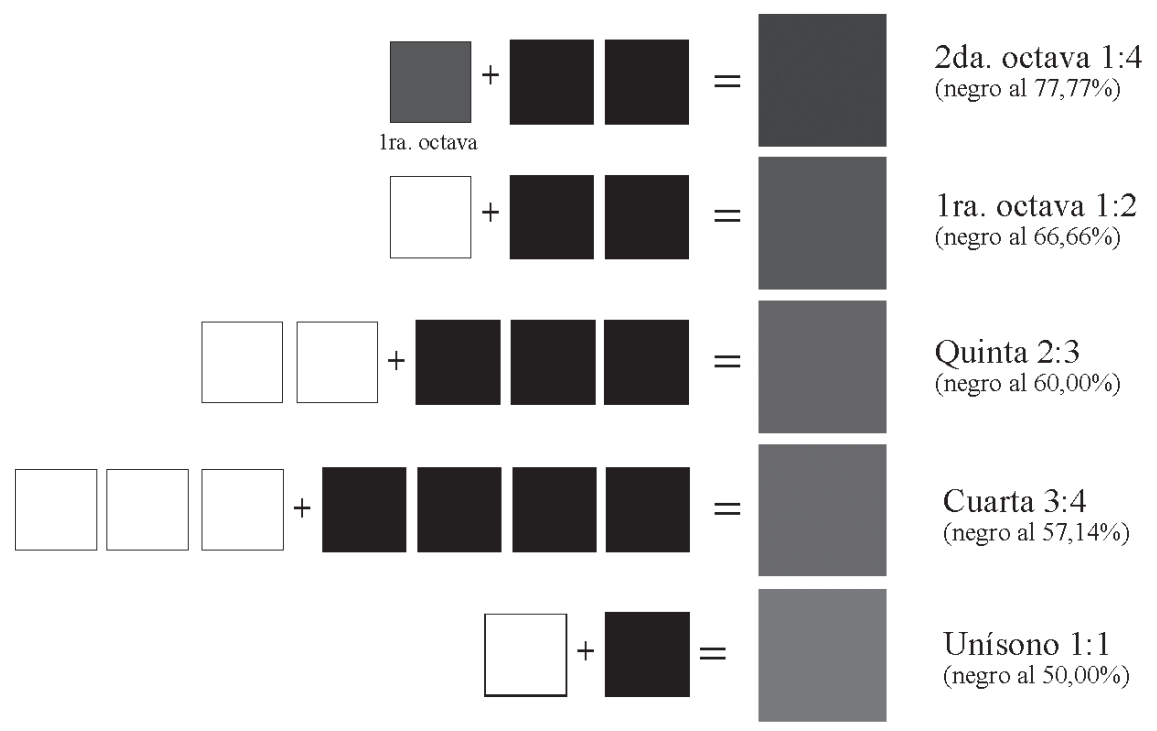

Figura 10. Interpretación de los intervalos “pictóricos” según Arcimboldo en Il Figino

1:2] y todas las otras consonancias musicales en sus colores con el mismo arte con el cual Pitágoras inventó las proporciones armónicas." COMANINI, 1591: 246-249. Puede leerse o descargarse, una versión facsímil en el enlace http://archive.org/download/ ilfiginooverodel00coma/ilfiginooverodel00coma.pdf y, también, puede revisarse una versión transcrita en http://www.memofonte. it/home/files/pdf/scritti_comanini.pdf (Revisado el 07-09-2012). De Gregorio Comanini (*Mantua, 1550; †Mantua, 1609), poeta italiano, se poseen pocos datos biográficos. Se conocen varias de sus obras literarias, entre las cuales destaca Il Figino, como una visión estética del arte de finales del siglo XVII.

39 Ibid. De esta metodología, y de la mención a los semituoni maggiore e minore, puede deducirse que el pintor manejaba proporciones propias de la "afinación justa", la cual Zarlino había racionalizado y sistematizado en su tratado Le Institutioni Harmoniche de 1558, y Kepler utilizaría en su Harmonices Mundi. Nótese también que el blanco, entendido como sonoridad grave y el negro asociado a lo agudo, puede resultar extraño dada nuestra actual tendencia de asimilar el brillo de los agudos con el brillo de la luz. Esto es sólo posible de comprender si se asume que, para la época, el blanco es tan solo un soporte de donde se ha sustraído todo, un vacío, un silencio, lo no audible. Una vez que el negro comienza a entrar en contacto con esta base blanca comienza a producirse el efecto pictórico y con ello el sonoro. La idea del blanco como resultado "aditivo" de todos los colores del espectro es una idea que sólo se establece después del siglo XVIII. 
Luego lo aplicaría a los colores al tomar como base una secuencia "ascendente" como sigue: amarillo, verde, azul, morado, marrón y, partiendo de esto, procedía a crear sus escalas "cromáticas" en la medida que

[...] il bianco e ombreggiato dal giallo, e 'l giallo dal verde, e ' 1 verde dall'azzuro, e l'azzuro dal morello, e 'l morello dal tanè, come il basso è seguito dal tenore, e 'l tenore dall'alto, e l'alto dal canto." 40

Asimismo, la corte de Rodolfo II era reconocida, pictóricamente hablando, como uno de los centros del llamado manierismo internacional. Este estilo, heredero de los logros técnicos y estéticos del Renacimiento, evolucionó hacia una autoconsciente artificiosidad y una alambicada técnica que derivó en figuras estilizadas, poses complejas y temáticas que variaban desde lo mitológico, lo bíblico y lo histórico, hasta lo erótico, lo grotesco y lo bizarro.
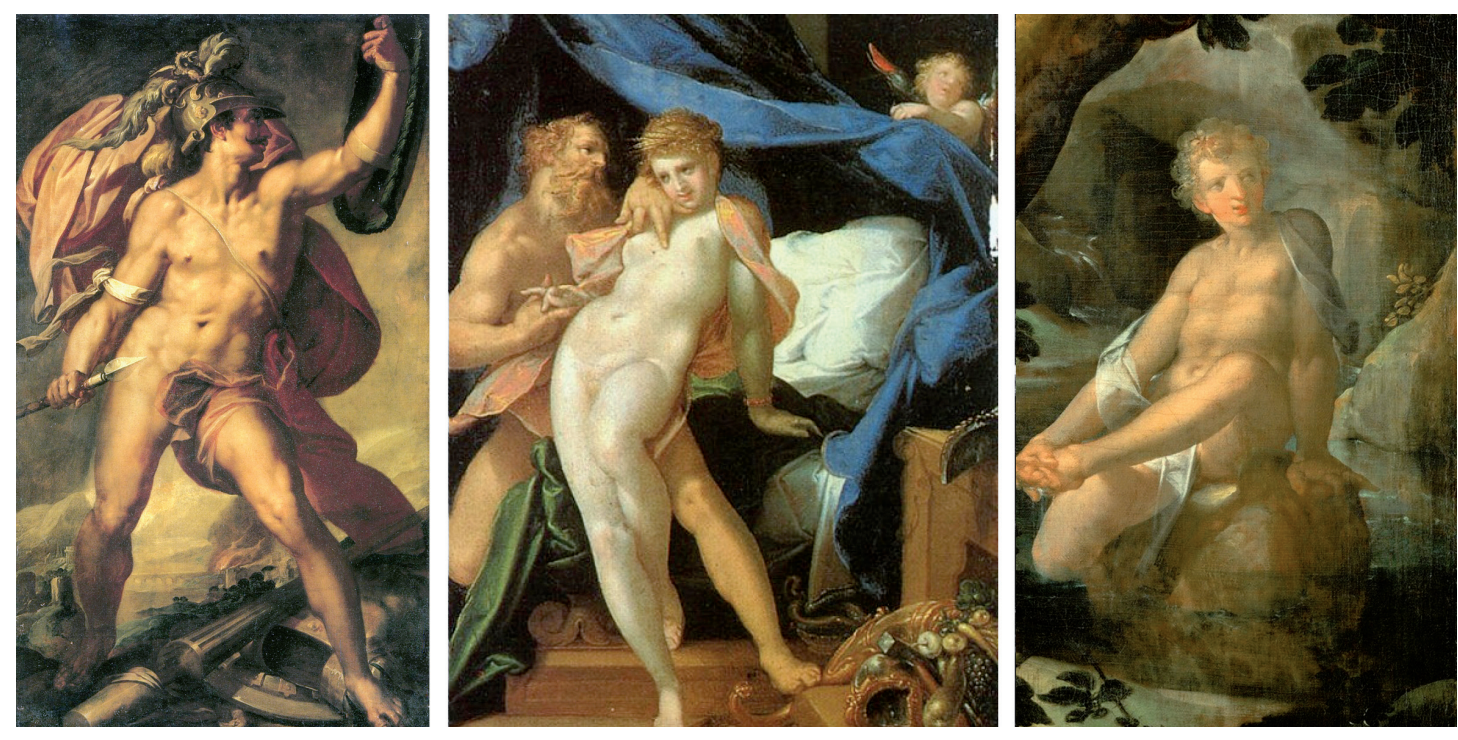

Figura 11. Obras de Bartholomeus Spranger (*Amberes, 1546; $†$ Praga, 1611). De izquierda a derecha, pinturas en la Galería de Pintura del Museo de Historia del Arte en Viena: Marte (1580);

Venus y Vulcano (1610); Salmacis y Hermafrodito (detalle, 1580)

40 Ibid. "[...] el blanco se oscurece por el amarillo, el amarillo por el verde, el verde por el azul, el azul por el morado, y el morado por el marrón, tal y como el bajo es seguido por el tenor, y el tenor por el contralto y el contralto por el soprano." Comanini nos informa también que se pudo ubicar en el gravicémbalo del compositor y organista de la corte, Karl Luython (*Amberes, 1557?; †Praga, 1620), todas las escalas y proporciones armónicas que Arcimboldo había marcado en colores en una hoja de papel. El gravicémbalo de Luython era un instrumento, similar al clavicémbalo, con un teclado de cuatro octavas, en el cual se habían insertado teclas entre el Mi y el Fa y entre el Si y el Do, para poder tocar los géneros cromático, enarmónico y diatónico. 
Bartolomeus Spranger -establecido en Praga desde 1581-, es el pintor que permite entrar en ese centro del mundo artístico de la corte. En sus obras, cargadas de gran contenido erótico, percibimos un tratamiento de lo masculino y lo femenino similar a lo expresado por Kepler en su Libro III, respecto, tanto de la naturaleza sexual de los modos durus-mayor y mollis-menor, como de la existencia de sólidos "andróginos" o "hermafroditas." ${ }^{41}$ Spranger hace lo mismo en el tratamiento de sus personajes, en donde lo masculino y lo femenino se presentan, según el historiador social del arte Arnold Hauser,

[...] con efectos sexuales insólitos y no acostumbrados [...] Los hombres aparecen demasiado masculinos y su virilidad demasiado acentuada, y las mujeres demasiado delicadas e infantiles, demasiado abandonadas sin protección a la violencia $[\ldots]^{42}$

De manera similar, Kepler se refería a "notables matrimonios" entre sólidos geométricos "masculinos" y "femeninos" en función de la manera en la que coinciden los vértices y las caras de cada uno de ellos, cuando se anidan unos con otros.
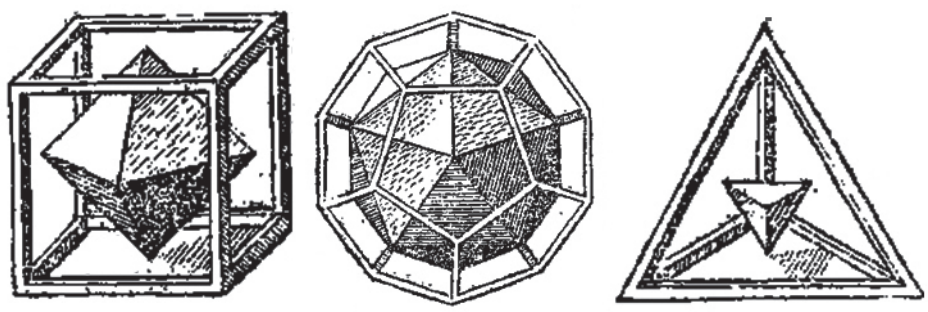

Figura 12. A la izquierda, el "matrimonio" entre cubo y octaedro; al centro, entre dodecaedro e icosaedro y, a la derecha, el tetraedro, que por ajustarse consigo mismo es considerado por Kepler un sólido “célibe” o "hermafrodita.” KEPLER, 1619, V: 181

Estos paralelismos permiten interpretar que los contenidos sexuales que Kepler incorporaría en su obra astronómico-musical -como se verá más adelante-, son manifestaciones del quehacer intelectual de una corte que consideraba a lo erótico, como un componente teórico de gran capacidad explicativa. El lienzo Venus y Vulcano de Spranger (ver Figura 11), es contemporáneo de la carta que Kepler envió a Joachim Tanckius en la que se explayaba en sus alegorías geométrico-sexuales. ${ }^{43}$ 396-397.

41 El término original usado por Kepler es androgynos y se encuentra en, KEPLER, 1619, V: 181; 1937, vol. 6: 293; 1997:

42 HAUSER, 1972: 245. Traducción al castellano de la segunda parte de HAUSER, 1965: 253.

43 Como se verá más adelante, Kepler desarrolla un curioso razonamiento en el que se observan figuras geométricas "copulando" y una referencia directa a "penes" y "vulvas". Puede verse, infra, los gráficos al final del Apartado 3.2. Joachim Tanckius (o Tancke) (*Perleberg, 1557; †Leipzig, 1609), fue profesor de anatomía, cirugía y Rektor de la Universidad de Leipzig en 1593, además de hombre interesado en la astronomía, la alquimia y sus relaciones con la medicina. 
Así entonces, durante la estancia de Kepler en Praga, puede verse cómo las experiencias estéticas que provienen de la música y la omniexplicativa teoría de las proporciones armónicas, conviven con la descripción astronómica, las formulaciones alquímicas y con la creación de teorías del color, los gradientes de la luz a sombra, y el erotismo andrógino. Si bien la armonía no fue la preocupación principal de Kepler, no cabe duda que el ambiente de la corte ha contribuido a añadir el fermento adecuado para la futura gestación del Harmonices Mundi.

\subsection{Linz: la redacción del Harmonices Mundi}

En el año fatídico de 1611, la realidad social, política y religiosa, hizo que Kepler abandonara Praga. Es decir, a la debacle anímica e intelectual de Rodolfo II y la sucesión al trono de su hermano Matías, se sumaron los estragos y persecuciones de la Guerra de los Treinta Años, haciendo que Kepler buscara refugio en Linz.

El evento más importante de la vida de Kepler en Linz fue, precisamente, la redacción del Harmonices Mundi y todo lo que ello supone; es decir, la lectura en profundidad de los tratados musicales que tenía a la mano y los que recibiera durante este período. Se sabe que hasta ese momento habría leído directamente, además de la obra armónica de Ptolomeo, las obras de Aristoxeno, las atribuídas a Euclides y las de Boecio; también, tratados de autores contemporáneos como L'arte del contraponto de Artusi y el Dialogo de Vincenzo Galilei. ${ }^{44}$ Con todo este conocimiento acumulado y las ya mencionadas postergaciones, el período en Linz quedó también marcado por varios eventos que contribuyeron a prolongar aún más la redacción definitiva de la obra: el enfrentamiento con las autoridades eclesiásticas de la ciudad por diferencias dogmáticas (Kepler negaba la doctrina de la ubicuidad del cuerpo y el espíritu de Cristo y, por ello, se le negó la comunión), el juicio por brujería contra su madre (once meses de prisión para la anciana acusada de administrar pociones mágicas) y, en especial, el ambiente turbulento que llevaría al inicio de la Guerra de los Treinta Años en 1618. Todo esto, prácticamente, en la misma semana de mayo en que Kepler alcanzara su gran logro astronómico: la Tercera Ley Planetaria. A estos procesos que lo agobiaban se sumó la aflicción por la pérdida de su hija Katherine en febrero de 1618. Tal vez, por todo esto, y como movido por un ansia de escape, Kepler escribió:

\section{[...] dimissis ego Tabulis, quae quietem requirunt, animum ad Harmonica excolenda appuli, $[\ldots]^{45}$}

44 Puede verse, en detalle, este inventario de las obras teóricas musicales conocidas por Kepler para esta fecha, en DICKREITER, 1973: 139-146. ARTUSI, 1586; Artusi (*Bologna, h.1540.; †Bologna, 1613) fue compositor y crítico de las tendencias modernas de la música de su época, siendo devoto de las teorías de su maestro Zarlino. GALILEI, 1581; Vincenzo Galilei (*Santa Maria a Monte, 1520; †Florencia, 1591) además de alumno de Zarlino y padre del célebre físico Galileo Galilei, fue compositor y ejecutante de laúd. Fue el líder del movimiento que revivió (a través de la vuelta a la monodía) los ideales poéticos y musicales de la Antigua Grecia. Se enzarzó en polémica con su maestro Zarlino en torno a la naturaleza de los intervalos y el importante papel que la práctica podía tener en la música, por encima de toda numerología o mera especulación teórica.

45 " "[...] dejé a un lado las Tablas [Rudolfinas] porque requerían sosiego y dirigí mi espíritu hacia la finalización de la Armonía.” Carta de Kepler a Wacker von Wackenfels, comienzos de 1618. KEPLER, 1937, vol. 17: 254. Wacker von Wackenfels 
Así entonces, de febrero a mayo del año 1618, Kepler se decidió a culminar la tan postergada obra. Es menester recordar que, casi unos veinte años atrás, en 1599 y estando aún en Graz, Kepler había escrito a Herwart von Hohenburg sobre el plan de la obra y, en especial, le había comunicado su proclama astronómico-musical:

[...] ut si daretur aer in caelo, certissime sit futurus concentus. ${ }^{46}$

Sin embargo, las medidas contrarreformistas de aquella época (sanciones en dinero, obligaciones rituales católicas, expulsión de predicadores y persecución a ciudadanos protestantes) lo obligaron a partir de la ciudad y dejar de lado, tanto el hipotético aire, como la música y las armonías celestes. Finalmente, en esos cuatro meses de 1618, trás un acopio de veinte años de filosofía, matemáticas, astronomía y música, todo halló su respectiva forma real: intelectual y numérica; visual y sonora.

\section{EL HARMONICES MUNDI: INTERSECCIONES, TRASLACIONES E INTERCAMBIOS ENTRE MÚSICA Y ASTRONOMÍA}

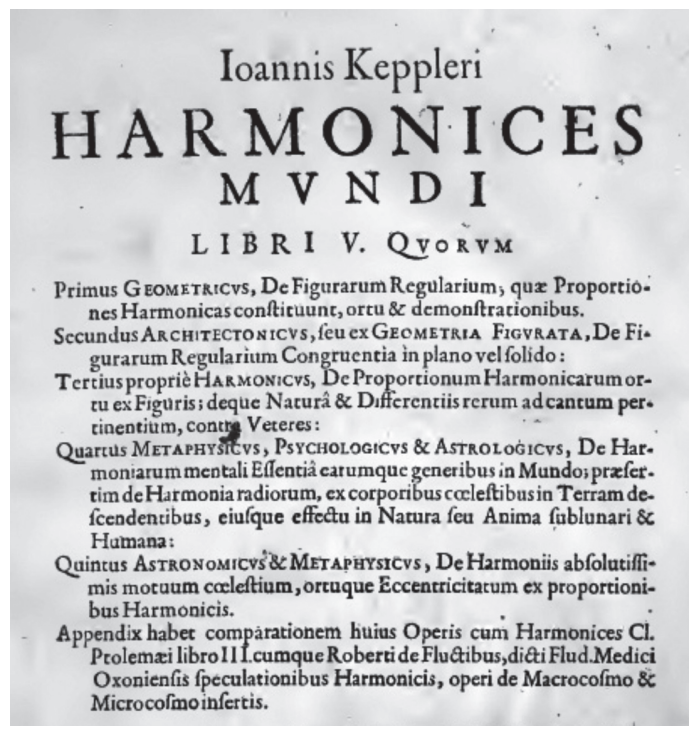

Figura 13. Detalle de la portada del Harmonices Mundi, en su primera edición de 1619,en la que se muestra el plan de la obra según sus cinco libros, que incluyen: geometría, arquitectura o geometría figurada, armonía, metafísica, fisiología, astrología, astronomía y metafísica

(*Constanza, 1550; †Viena, 1619) fue consejero real de Rodolfo II y un intelectual con intereses en filología, historia y filosofía. Amigo de Kepler, éste le dedicó, como regalo de año nuevo, su opúsculo sobre el copo de nieve hexagonal: KEPLER, 1611.

46 "Dad aire al cielo y, real y verdaderamente, sonará la música." Carta de Kepler a Herwart von Hohenburg del 6 de agosto de 1599. KEPLER, 1937, vol. 14: 27. 
El traspaso de metodologías y conceptos entre los dominios de la música y la astronomía es fundamental para poder comprender la manera en la que Kepler construye su filosofía natural respecto al Harmonices Mundi. El mismo Kepler expuso claramente este encuentro disciplinario cuando, al querer distanciarse de la antigua propuesta armónica y astronómica ptolemaica, decía haber corregido la astronomía eliminando la mera y trivial interpretación simbólica, puesto que, ahora, estaban allí

Harmonicas proportiones omnes, Harmoniarum genera, systema seu scalam Musicam, et claves ejus plerasque, Tonorum varietates, vocum figuralis musicae aemulos planetas, contrapuncta denique universalia 6 primariorum planetarum, variata et generibus et tonis. ${ }^{47}$

Ésta es la cara musical de una astronomía que invita a comprobar -visual y acústicamente- cómo toda esta panoplia se encuentra en los cielos. En otras palabras, la música como experiencia estética y la armonía como fundamento teórico, son los contextos verdaderos en los que esta formulación científica puede y debe verificarse, tal y como se intentará explicar a continuación.

\subsection{Antecedentes: el papel de la Armonía de Ptolomeo y la teoría geométrica de la consonancia}

Las reflexiones armónicas de Kepler están salpicadas, según nos dice, del azar y las coincidencias fortuitas. En las notas publicadas a la edición de 1621 del Mysterium Cosmographicum, nos aclaraba, retrospectivamente, que el inicio de sus especulaciones armónicas había nacido como una "gran suerte" -foelicitas - al reparar en la finitud de las proporciones armónicas. ${ }^{48}$ Para Kepler era sorprendente que, a pesar que desde la antigüedad hubo escritores sobre temas de armonía, ninguno hubiera reparado en las coincidencias fortuitas entre el número de proporciones armónicas y las siete notas naturales en la escala. Estas siete notas podían reagruparse en forma de cinco consonancias (octava, quinta, cuarta, sextas y terceras) y hacerlas coincidir con los cinco sólidos platónicos. ${ }^{49}$

47 “Todas las proporciones armónicas, los tipos de armonías, el sistema musical o escala en casi todas sus claves, la variedad de tonos, los planetas que emulan la música figurada vocal y, finalmente, el contrapunto universal de los seis planetas principales, y sus variados tipos y tonos." KEPLER, 1619, V: 251; 1937, vol. 6: 372; 1997: 503.

48 KEPLER, 1596. Conocido como el Mysterium Cosmographicum, si bien era un libro anterior al Harmonices Mundi de 1618 , su segunda edición de 1621 incluía una serie de notas y comentarios de carácter retrospectivo sobre los procesos de descubrimiento y elaboración de teorías por parte del propio Kepler. Véase la edición al castellano en KEPLER, 1992. Puede verse y descargarse una versión digitalizada de la edición de 1621 en http://www.e-rara.ch/doi/10.3931/e-rara-445 (Revisado el 07-092012). Más adelante (véase infra "Sumario de teoría astronómica" en el Apartado 3.2), se exponen algunos aspectos de este libro que fueron de importancia para el Harmonices Mundi.

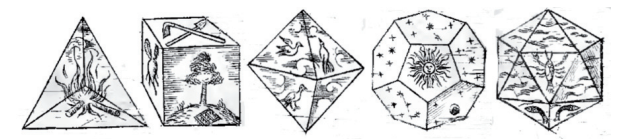

Los "sólidos platónicos" son: tetraedro, cubo o hexaedro regular, octaedro, dodecaedro e icosaedro. También conocidos como sólidos "pitagóricos" o "perfectos”, son un conjunto de cinco, y sólo cinco, poliedros que cumplen ciertas condiciones geométricas: sus caras son polígonos regulares iguales y, un mismo número de caras (tres), se encuentran en cada vértice. Descritos por Platón en su diálogo Timeo, eran asociados a los elementos (tierra, fuego, agua y aire) y a una quinta sustancia de la cual estaría compuesto todo el orbe celeste. Kepler sería uno de los tantos geómetras que 
Para Kepler estas coincidencias podían experimentarse, incluso, con un improvisado monocordio, es decir:

[...] cum tam sit obuium cuilibet, id in chorda quacunque extensa, cuius spatium subiectum circino diuidi possit, simplici applicatione rei durae, vt cultri aut clauis, ad chordam manu vna, et percussione partium eius interstinctarum cum plectro in manu altera, experimentari. ${ }^{50}$

Así, todas estas preguntas: “¿por qué seis planetas?, ¿por qué cinco sólidos perfectos?, ¿por qué siete notas y siete divisiones armónicas?, ¿por qué cinco consonancias?, pertenecían todas a un mismo espacio epistémico, y por ello Kepler va tras la búsqueda de una respuesta que debería ser común y no fortuita.

El proceso por medio del cual lo musical se convertiría en la obsesión principal y reclamo constante, puede precisarse con detalle a través de la correspondencia con su maestro Maestlin, con Edmund Bruce, y en especial, en la compartida con Herwart von Hohenburg entre el verano y el invierno de $1599 .{ }^{51}$ En esta correspondencia, Kepler, además de dejar claro el dominio que posee sobre los temas musicales y armónicos, explicaba cómo su propósito había sido particularmente "incitamentum lectio Harmonicorum Ptolemaei" ${ }^{52}$

Para Kepler, Ptolomeo -hacía más de mil quinientos años- había tenido sus mismas intuiciones, con la diferencia de que, ahora, él se basaba en una argumentación totalmente nueva e inusual para justificar las consonancias: a partir de las relaciones que se producían en un círculo cuando éste era segmentado por un polígono regular inscrito en él. A diferencia de Ptolomeo, que se basaba en el monocordio tradicional, Kepler dedujo, ingeniosamente, las siete proporciones armónicas al correlacionar un Todo, unas Partes y un Residuo en un curioso monocordio circular, cuya realización material consideró irrelevante. A manera de ejemplo, en el caso particular del círculo segmentado por un pentágono, Kepler tomaba uno o más lados del polígono tal, que la suma de ellos no excediera la mitad del círculo, y tenía:

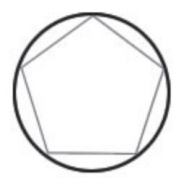

Todo $=5$
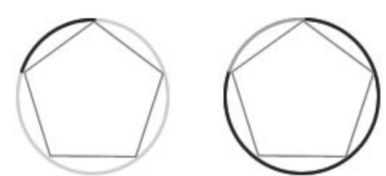

Partes $=1 \quad$ y Residuo $=4$
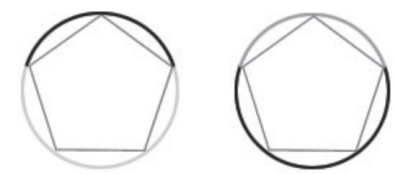

Partes $=2 \quad$ y Residuo $=3$

quedaría fascinado por dichas propiedades y también haría referencia a sus simbolismos -figurae mundanae-, tal como escribe y se observa en la ilustración expuesta en el Harmonices Mundi. Véase KEPLER, 1619, II: 58-59; 1937, vol. 6: 79-80; 1997: $111-114$.

50 " $[. .$.$] pues resulta obvio para cualquiera experimentar esto sobre una cuerda extendida, cuya longitud puede ser dividida$ con un compás, y con la mera aplicación de una cosa dura, como un cuchillo o una llave, a la cuerda con una mano, mientras se golpea con un plectro las partes delimitadas de la cuerda, con la otra mano". KEPLER, 1937, vol.8: 72. Véase "Nota 8 al Capítulo XII" en KEPLER, 1992: 139.

51 Michael Maestlin (*Göppingen, 1550; †Tübingen, 1631) fue un astrónomo y matemático, más que todo conocido por ser el maestro de Kepler. Fue profesor de matemáticas en la Universidad de Tübingen, durante cuarenta y siete años, desde 1583. Unas mínimas referencias biográficas a Edmund Bruce y Herwart von Hohenburg pueden verse, supra, en las Notas 28 y29, respectivamente.

52 “[...] estimulado por la lectura de los Armónicos de Ptolomeo [...]”. KEPLER, 1937, vol.6: 289. Los Armónicos de Ptolomeo, en forma de manuscrito en griego, fueron finalmente enviados, en 1607, a Kepler por Herwart von Hohenburg. Hay traducción en BARKER, 1989. 
Al realizar las comparaciones se obtenía:

- Parte a Residuo. Proporciones: [1:4] y [2:3].

- Parte a Todo. Proporciones: [1:5] y [2:5].

- Residuo a Todo. Proporciones: [3:5] y [4:5].

Para limitar las múltiples posibilidades, un grupo de axiomas (que pueden resumirse en tres condiciones básicas), definían las consonancias:

a) Los polígonos regulares que no pueden construirse por métodos geométricos, no producen consonancias. ${ }^{53}$ Solo son admitidos el diámetro del círculo y las figuras fundamentales expuestas en el Libro I que poseen una correcta construcción: triángulo, cuadrado, pentágono, hexágono, decágono y dodecágono.

b) Las proporciones múltiplos una de otra, se consideran idénticas. Así las proporciones [1:2] ; [1:4]; [1:8] al igual que [2:3] ; [4:6] y [8:12] etc., se consideran idénticas, al igual que la proporción [1:3] respecto de [2:3].

c) Se excluye también cualquier proporción conseguida en un polígono regular que pueda provenir de un polígono no construible. Así, del octágono podemos obtener la relación parte a residuo del tipo 1:7, pero se excluye por derivarse también del heptágono - polígono no construible-.

El resultado final podría expresarse, gráficamente, de la siguiente manera:

53 Se entiende aquí por un polígono regular “construible por medios geométricos” aquellos que, según los métodos de la geometría tradicional griega, eran posibles de construir (dibujar) a través de los procedimientos clásicos euclidianos de regla y compás. En este sentido "polígonos construibles" eran los polígonos regulares de 3, 4, 5 y 15 lados, así como aquellos múltiplos, provenientes de biseccionar el ángulo interior (así, el octágono puede construirse a partir del cuadrado y, el decágono a partir del pentágono). Para otros polígonos regulares, como el heptágono (siete lados), el eneágono (nueve lados) y otros cuya suma de lados fuera un número primo, no se conocían, para la época de Kepler, métodos para su construcción, a través de regla y compás. 

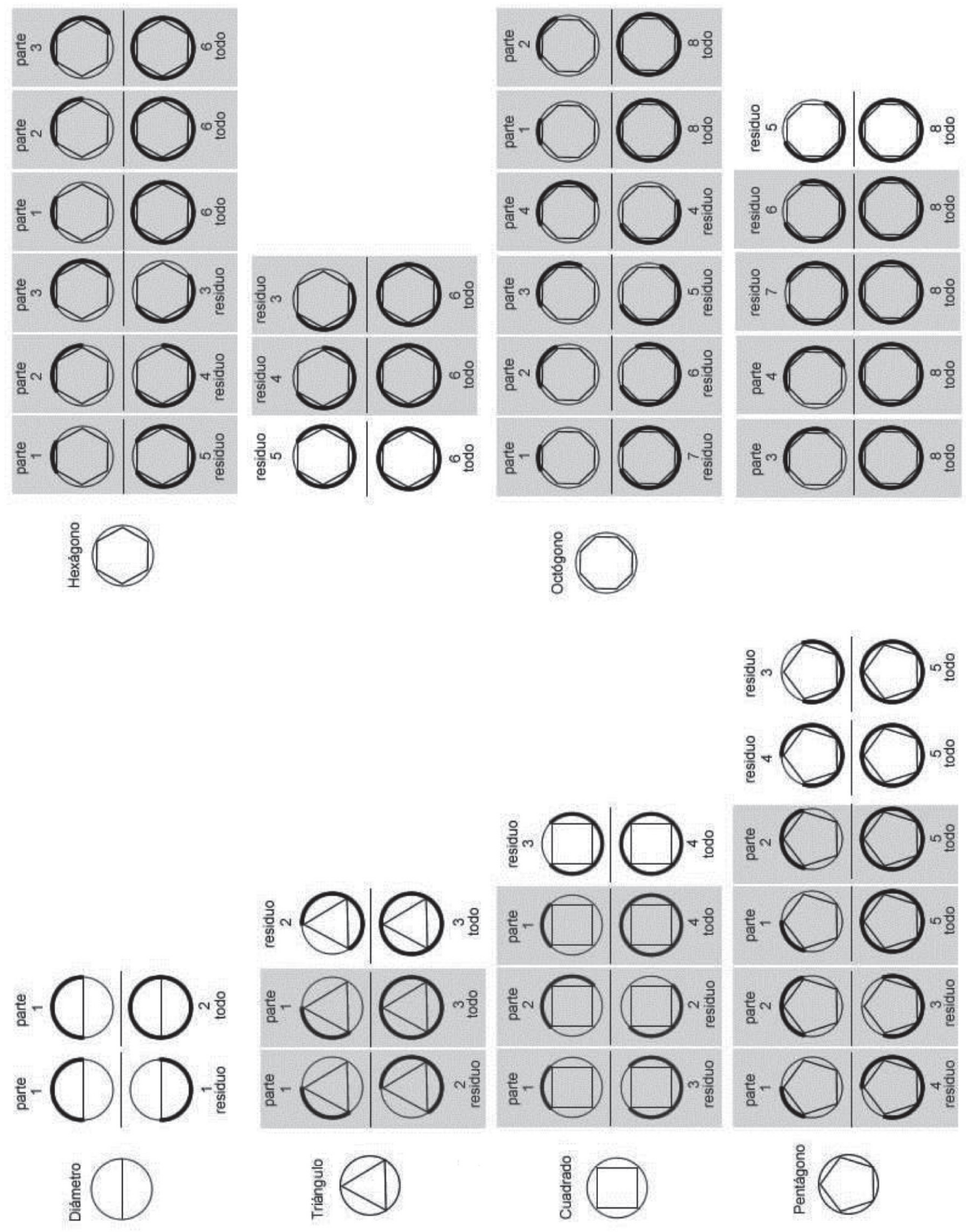

Figura 14. Selección de consonancias según la teoría musical de Kepler. Sobre fondo blanco, los polígonos básicos junto a las consonancias seleccionadas y, sobre fondo gris, las proporciones excluidas, por ser idénticas o múltiplos de una ya previamente hallada 
El resto de los polígonos "construibles" producían consonancias que eran réplicas o equivalencias de las anteriores. A través de este ingenioso y original argumento -nunca hecho hasta entonces-, Kepler obtuvo, de todo el universo geométrico de las figuras planas, el esquema de siete consonancias básicas que coinciden con la llamada afinación justa, tal y como fuera expuesta por Zarlino. Este esquema sirvió a Kepler para justificar y asumir, como paradigma de la música y expresión suprema de los arquetipos geométricos del Creador, la polifonía de compositores como Orlando di Lasso, que utilizaba de manera acertada y expresiva las terceras y sextas..$^{54}$

\subsection{La teoría musical kepleriana: del modo al sexo}

Una vez que el lector quedara convencido de que las proporciones armónicas podían ser deducidas de la geometría del círculo, Kepler las reafirmó, de manera sensible, con el juicio del oído, como las únicas consonancias posibles. A partir de aquí, pudo construir una teoría musical cuyo complejo proceso se iniciaba con la construcción de los seis casos posibles de organización de las consonancias del tipo 3:4, 4:5 y 5:6 en el marco de una doble proporción u octava 1:2.

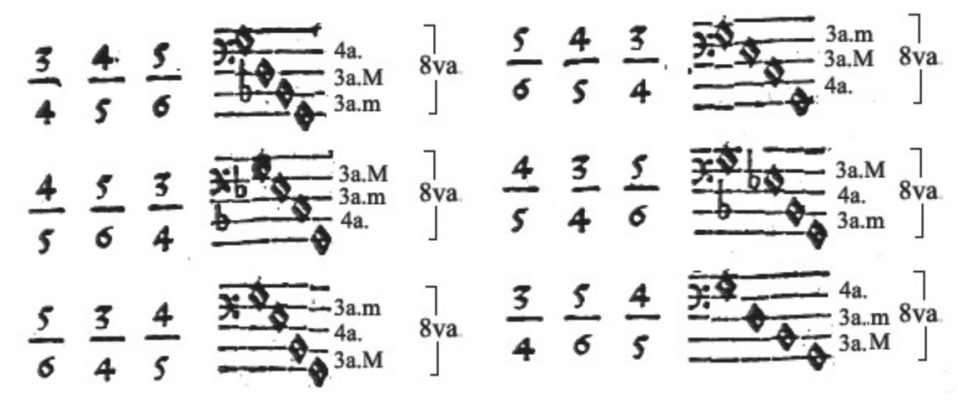

Figura 15. Combinatoria de intervalos en una octava, según la teoría musical de Kepler

Luego, Kepler construía los pequeños intervalos consonantes melódicos (Tonos mayores y menores, Semitonos, Limmas y Diesis) al realizar sustracciones entre las consonancias mostradas anteriormente: ${ }^{55}$

o La 5ta. menos la 4ta. produce un Tono mayor. 2:3 - 3:4 = 8:9.

o $\quad$ La 6ta. mayor menos la 5ta. produce el Tono menor. 3:5 - 2:3 = 9:10.

54 Véase, supra, Nota 31 al respecto de los motetes mencionados por Kepler en el Harmonices Mundi y el valor de estas consonancias.

55 Recuérdese que en la aritmética de proporciones la "suma" equivale a multiplicar las fracciones equivalentes, y la "resta", a dividirlas. 
o La 4ta. menos la 3era. menor produce, igualmente, el Tono menor. 3:4 - 5:6= 9:10.

o $\quad$ La 6ta. menor menos la 5ta. produce el Semitono. 5:8 - 2:3 = 15:16.

o La 4ta. menos la 3ra. mayor produce, igualmente, el Semitono. 3:4 - 4:5 = 15:16.

o La 6ta. mayor menos la 6ta. menor produce la Diesis. 3:5 - 5:8 $=24: 25 .^{56}$

o La 3ra. mayor menos la 3ra. menor produce, igualmente, la Diesis. 4:5 - 5:6 = 24:25.

o $\quad$ El Tono mayor menos el Semitono produce la Limma. 8:9 - 15:16 = 128:135.

o $\quad$ El Tono mayor menos el Tono menor produce la Comma. 8:9 - 9:10 = 80:81.

$\mathrm{Al}$ insertar estos pequeños intervalos entre las notas de los esquemas anteriores, construyó su pleno et perfecto Systemate organico, cuya estructura ascendente de intervalos, era la siguiente ( $\mathrm{L}=\mathrm{Limma}, \mathrm{S}$ $=$ Semitono, $\mathrm{D}=$ Diesis $)$ :

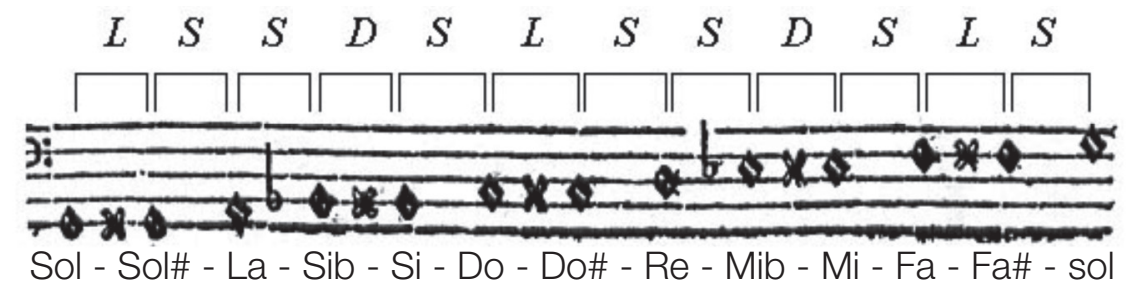

Figura 16. Sistema “orgánico, completo y perfecto” según la teoría musical de Kepler

Este proceso tenía como objetivo, básicamente, ofrecer una explicación de los llamados Modos Eclesiásticos. ${ }^{57}$ Para ello, a través de una serie de razonamientos propios y una serie de reglas para la sucesión de tonos y semitonos de una melodía correcta, Kepler obtuvo un total de veinticuatro modos (catorce básicos y diez variantes) que le permitían demostrar que los ocho Modos Eclesiásticos, eran casos particulares de su propia teoría, más general..$^{58}$

56 Kepler denominaba aquí como diesis, a lo que en la "afinación justa" era denominado como "semitono menor". Igualmente, al intervalo de proporción 128:135 (que debe entenderse como el semitono menor de proporción 24:25 más la coma sintónica de proporción 80:81) Kepler lo denomina limma, cuya proporción, en la tradición pitagórica, era 243:256. Véase infra Nota 74, una aclaratoria más precisa en torno al uso de estos términos de parte de Kepler.

57 El término 'Modos Eclesiásticos' se refiere aquí a la sistematización que hizo la Iglesia, a lo largo de la Edad Media, del material musical que utilizara para su liturgia. En este sentido, como es sabido, un "modo" es una secuencia ordenada de tonos y semitonos que permite -al restringirse a ellos- entonar diversas melodías con un particular sentido expresivo. Desde la antigüedad y hasta el siglo XVII los modos fueron evolucionando, no sin ciertas diatribas y debates, tanto en torno a sus nomenclaturas, como a su manera de estructurarse. Kepler se encargaría de advertir de no querer entrar en esas disputas, tal como escribiera en la introducción a este tema en el Cap. XIV de KEPLER, 1619, III: 66; 1937, vol. 6: 163; 1997: 224. No obstante, para desarrollar su investigación, Kepler se ceñía a la manera más consensuada en que se trataban estos modos, la cual se encontraba en muchos de los tratados musicales utilizados por el mismo Kepler.

58 Todo este complejo proceso y encadenamiento de razonamientos está expuesto en el Libro III y su explicación desborda los límites de este ensayo. Lo importante a señalar aquí, es la actitud del filósofo natural que, en el caso de Kepler, de manera propia 
Pero, el objetivo ulterior de toda esta teoría musical kepleriana era mostrar la "emotividad" que poseía cada uno de esos modos. Bajo el título "Qué modo y qué tono sirven para qué emociones”, Kepler aclaraba que cualquiera que fuese el modo seleccionado para una melodía, por poseer terceras o sextas, sean mayores o menores, quedaban a su vez definidos con una cualidad afectiva del tipo durus o mollis. ${ }^{59}$ Esta "emotividad" o "afectividad" se desbordaba hasta una índole "sexual”, pues quedaba claro para Kepler que la escala e intervalos de tipo durus poseían atributos decididamente "masculinos", así como los mollis marcadamente "femeninos". Kepler hacía la pregunta retórica:

Quae est igitur hujus situs connexio cum affectionibus? aut quid commune tertiae minori cum foeminis, cum passionibus, cum mollitie; quid item Tertiae durae cum virilitate, duritie, actionibus, efficacia? ${ }^{60}$

La curiosa respuesta - a tan curiosa pregunta- puede catalogarse de dos maneras: una simbólica y otra matemática, como a continuación se explica:

a) La argumentación simbólica estaba expuesta en el Cap. XV del Libro III, en el que Kepler comentaba que el intervalo mayor es asimilable al "gallo", altivo y masculino, puesto que al cantarse una tercera mayor (dos tonos), la naturaleza sonora del intervalo impele con "irrefrenable vigor" - $\alpha \kappa \mu \eta \alpha о \chi \varepsilon \tau о \zeta-a$ “eyacular" - $\varepsilon \kappa \chi v \sigma \iota \zeta-$ el semitono faltante, y así alcanzar la cuarta justa (dos tonos y un semitono). Mientras que, al cantar una tercera menor (tono y semitono), el semitono de la parte superior invita a descender, pasiva y femeninamente, hacia el tono

[...] veluti gallina, sternit humi, promptam insessori gallo. ${ }^{61}$

Kepler no duda en extrapolar esto a la mujer y al hombre; siendo así, para él, la mujer "pasiva" y el hombre "activo", sobretodo, a la hora del acto sexual o -en palabras de Kepler- in generationis negocio.

b) La argumentación matemática consistía en un curioso razonamiento que, involucrando al pentágono y sus propiedades geométricas, permitía a Kepler demostrar el carácter sexual -explícito ahora

y original, reconstruye toda la teoría musical desde sus fundamentos y como punto de partida para su posterior aplicación en el ámbito, tanto astrológico (Libro IV), como astronómico (Libro V). Por esta razón, Kepler culmina -como casi todo filósofo o científico intenta hacer- creando un nuevo marco conceptual que convierte al anterior, en un caso particular de la nueva teoría. Ya se ha visto cómo esto ha sucedido, en el caso de Kepler, con las consonancias derivadas -de manera inédita- de una teoría más general de la geometría del círculo y ahora, los ocho Modos Eclesiásticos como casos particulares de una teoría armónica, aún más amplia.

59 Recuérdese que los Modos Eclesiásticos I, II, III y IV por contener 3ras. y/o 6tas. menores, eran considerados mollis; los Modos Eclesiásticos 5to, 6to. 7mo. y 8vo., por contener 3ras. y/o 6tas. mayores eran considerados durus.

60 ¿Cuál es entonces la conexión de esta situación con los afectos? ¿Qué tienen en común la tercera menor con la mujer, con las pasiones [la pasividad] y con la suavidad; y también, la tercera mayor con la virilidad, la fuerza, la actividad y la eficacia?" KEPLER, 1619, III: 76; 1937, vol. 6: 175; 1997: 240. Aiton, Duncan y Field traducen "passionibus" por "passivity" (pasividad), seguramente, porque en esos párrafos puede entenderse como antónimo de "actionibus". Queda claro que, para Kepler, la mujer "padece".

61 “[...] como la gallina que se postra lista para que el gallo la posea.” KEPLER, 1619, III: 77; 1937, vol. 6: 176; $1997: 242$. $\mathrm{Al}$ respecto de la palabra griega $\varepsilon \kappa \chi v \sigma \iota \zeta$, Walker ha optado por traducir "ejaculate" y Aiton, Duncan y Field por "bursting out". Dado el evidente contenido sexual implicado en todo esto, es seductor inclinarse por la primera. Toda esta argumentación sobre la emotividad y sexualidad de los intervalos mayores y menores fueron expuestas por Kepler en dos momentos: en la carta del 12 de mayo de 1608 a Joachim Tanckius en KEPLER, 1937, vol 16: 154 y ss. y diez años después, en las argumentaciones del Cap.XV del Libro III del Harmonices Mundi: KEPLER, 1619, III: 74-80; 1937, vol. 6: 173-179; 1997: 238-246. 
visualmente- de cada cualidad, durus y mollis, y su relación con la reproducción y la generación. A continuación, el encadenamiento de argumentos según como están expuestos en el Libro III y han sido aquí resumidos en cinco pasos: ${ }^{62}$

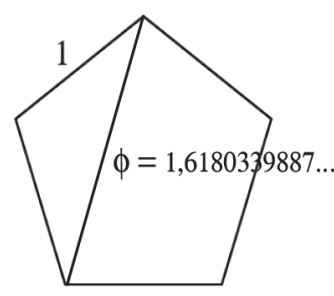

i) Se acepta que la tercera mayor proviene del pentágono, tal como pudo verse en la división del llamado monocordio circular. ${ }^{63}$

ii) Se acepta que el pentágono presenta la "divina proporción" entre el lado y su diagonal o lado de la estrella inscrita, tal como puede demostrarse fácilmente y se observa en la imagen. ${ }^{64}$

iii) La "divina proporción” tiene la propiedad de que, cuando la parte mayor es agregada al todo, la proporción se continúa. La nueva suma toma el lugar del todo y el anterior todo toma el lugar de la parte mayor. Esto la convierte en una figura arquetípica dado que,

In hac vero proportione pulchra inest Generationis idea. Nam sicut pater gignit filium, filius alium $[\ldots]^{6566}$

iv) Si la parte menor es el número 1, y la parte mayor el número 2, el todo sería el número 3. Queda claro que esta tríada de números no cumple la extrema y media razón pues si bien $1<2<3$, el 1 no es al 2 como el 2 es al 3. Además, si sumamos 2 al 3, el nuevo todo sería 5, y tampoco se cumple la proporción. No obstante, la nueva tríada $2<3<5$ se aproxima un poco más a la "divina proporción" que la tríada anterior. Ahora, si sumamos el 3 al 5 el todo se convertiría en 8 y, si bien la tríada $3<5<8$ sigue sin cumplir la “divina proporción", cada vez se aproxima más a ella. ${ }^{67}$

62 La serie de apartados que se enumeran desde i) a iv) son una breve sistematización de lo que, en el Cap. XV del Libro III, es un párrafo cuya argumentación y curioso razonamiento se ofrece de manera continua y podría parecer confusa. Ibid.

63 Véase supra Figura 14, la tercera mayor consonante a partir del pentágono circunscrito.

64 La "divina proporción” del pentágono -Divinam proportionem- estaba expuesta en la Definición XXVI del Libro I, en KEPLER, 1619, I: 15-16; 1937, vol. 6: 28-30; 1997: 29-31. Desde el punto de vista aritmético, esta proporción establece que dos cantidades, siendo a $<$, están en "divina proporción" si a : b como b : a + b. Es decir, la parte menor es a la mayor como la mayor es a la suma de las dos. También puede verse así: la secuencia $\mathrm{a}<\mathrm{b}<\mathrm{c}$ está en "divina proporción” si a : b : c, siendo c = a + b. Todo esto puede interpretarse, grosso modo, como la "aritmetización" de la divisa estética que sugiere que, la belleza proviene de la armonía de las partes entre sí y, a la vez, de las partes con el todo.

65 "Sin embargo, en esta hermosa proporción se encuentra la espléndida idea de la generación. Al igual que un padre engendra a un hijo, y el hijo a otros [...]". Se recuerda al lector que toda esta argumentación puede leerse en KEPLER, 1619, III: 74-80; 1937, vol. 6: 173-179; 1997: 238-246.

66

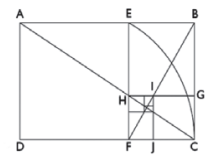

de rectángulos "divinos o "áureos", tal como se expedita de visualizar esta propiedad "hereditaria", es cierto que al sumarle a su lado menor, el lado mayor, se obtendría un nuevo rectángulo, también con dicha proporción. Y viceversa, si al lado mayor se le restara el lado menor, se obtendría también un rectángulo de "proporción divina". Si se repitiera la operación sobre cada nuevo rectángulo, se "generaría", siempre, el mismo tipo de rectángulo que, al decir de Kepler, "hereda" la propiedad del anterior como de "padres a hijos".

67 Como se nota, Kepler sugiere aquí la conocida "serie de Fibonacci” 0,1,1,2,3,5,8,13,21,34,...(n-1)+n. Como se sabe, la relación entre cualesquiera tres de estos números consecutivos, se aproxima, conforme la serie avanza, hacia la "divina proporción"; de manera que, en el límite, cuando "n" tiende a $\infty$, el cociente entre los dos últimos números tiende al número irracional $\Phi=1,6180339887 \ldots$ 
v) Dado que, en cualquier proporción del tipo, a:b como b:c, se tiene que $a \cdot c=b^{2}$, al evaluar estos productos sobre las sucesivas aproximaciones de cada tríada de números de la serie mencionada anteriormente $(0,1,2 ; \quad 1,2,3 ; \quad 2,3,5 ; \quad 3,5,8 ; \quad 5,8,13$; etc.), pueden expresarse, gráficamente, los resultados, en forma de estructura de cuadrados, a los cuales puede otorgarse una distinción sexual: "macho" según se posea un cuadrado como apéndice sobrante, o "hembra", si es un vacío faltante.

Así, si $\mathrm{a}<\mathrm{b}<\mathrm{c}$ son términos de una serie tipo Fibonacci, el producto a·c y el resultado b2, al representarlos gráficamente y compararlos geométricamente, se tiene

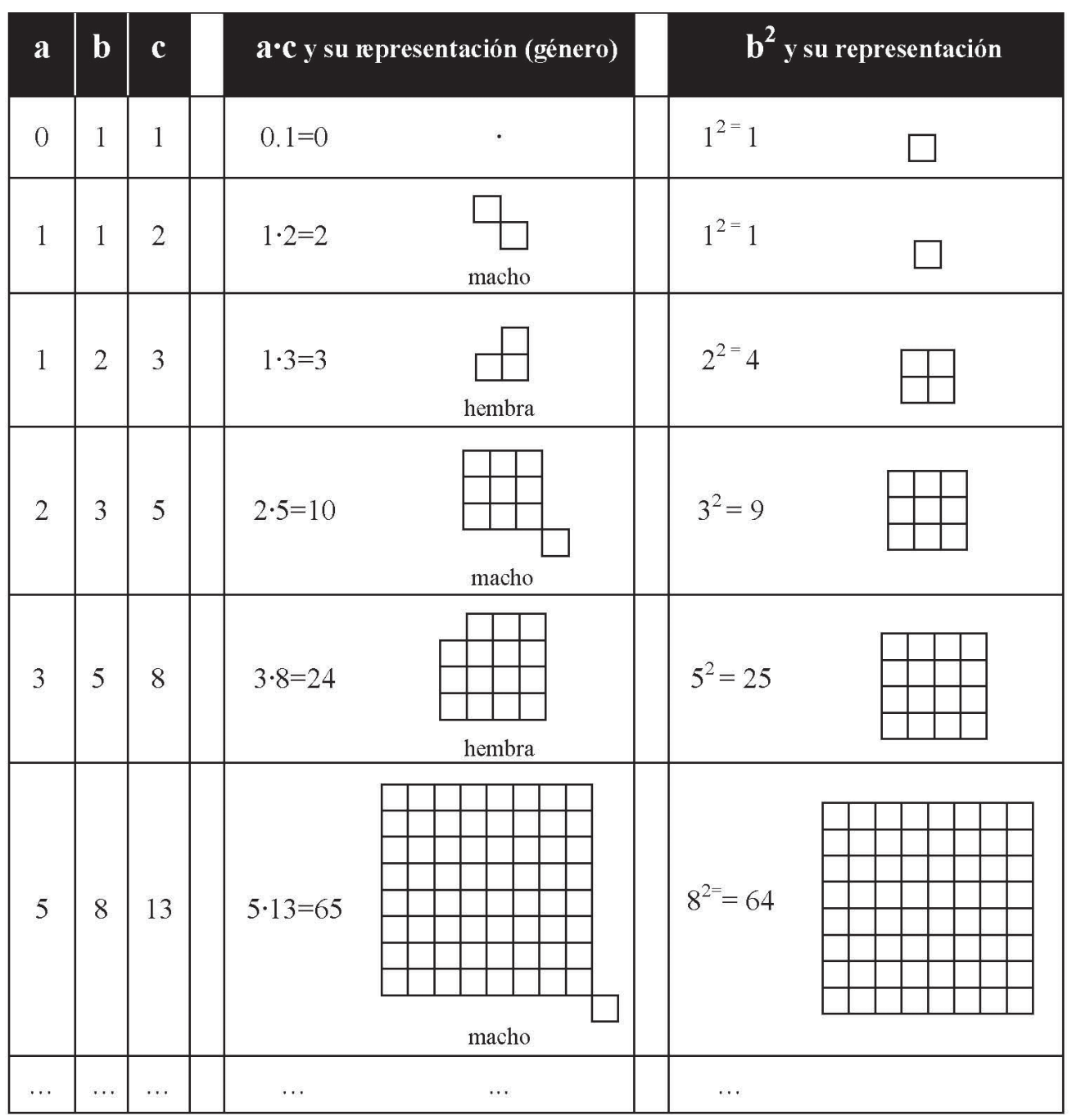

Como se observa en la columna "a·c", se alternan formas de "cuadrado-con-sobrante-macho" con formas de "cuadrado-con-faltante-hembra". En carta de mayo de 1608, al ya mencionado médico y anato- 
mista, Joachim Tanckius, Kepler mostraba el dibujo de estos seres geométricos que podían perfectamente acoplarse y, como acotación, escribía:

Non puto me posse clarius et palpabilis rem explicare, quam si dicam te uidere imagines illic mentulae, hic vulvae. ${ }^{68}$

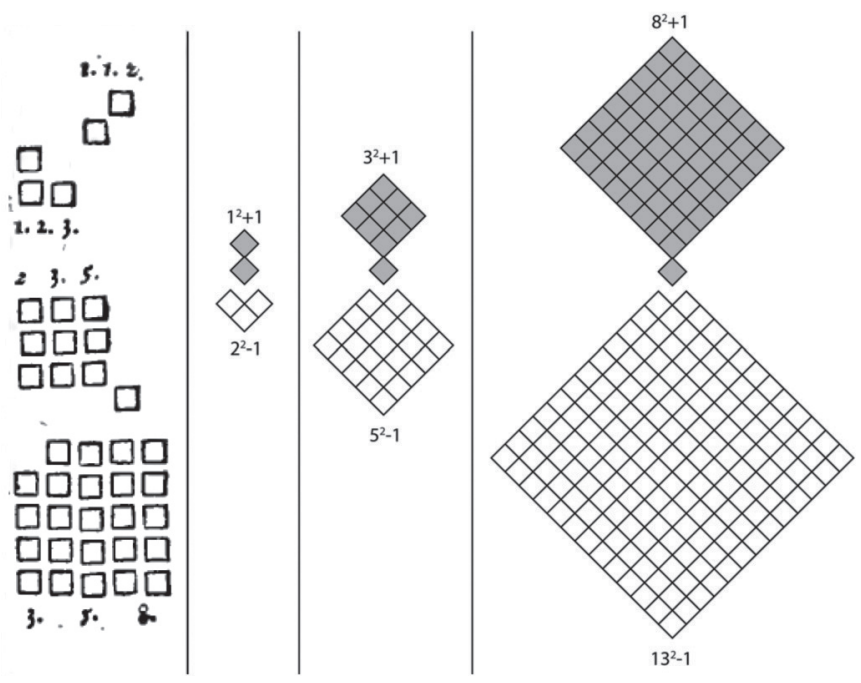

Figura 17. Ilustración original de Kepler e interpretación de los cuadrados y su cópula ${ }^{69}$

Lo importante a señalar aquí es que, intentando justificar la naturaleza y la relevancia de las cualidades durus-mayores y mollis-menores, la imaginación kepleriana ha logrado conectar la geometría con los intervalos musicales y, a la vez, con un carácter vital, emotivo y sexual implícito, según él, en ello. Todo esto, finalmente, quedaría expresado en el Libro V donde se definiría con exactitud la "doble manera" de estar "afinado" el universo, igualmente durus-mayor-masculina y otra mollis-menor-femenina, lo que le permitiría afirmar que la gigantesca polifonía de los planetas, tendría las dos posibilidades: macho o hembra. En otras palabras, al igual que las criaturas de Dios, o la "divina proporción” o, incluso, los libidinosos cuadrados, el universo también manifestaría una continua alternancia entre lo "masculino" y lo "femenino". Así como aquellos garantizan su existencia constante a través de sus mecanismos de

68 "No puedo pensar una manera más clara y palpable de explicar esto, como si dijera mira allá las imágenes de los penes, aquí las de las vulvas.” KEPLER, 1937, vol. 16: 157.

69 Es fácil notar que. conforme crecen los términos de esta serie, las estructuras de cuadrados lo hacen también hasta, prácticamente, volverse minúsculos e insignificantes sus atributos sexuales. Aunque Kepler no mencione este detalle, puede permitirse suponer que en el límite al infinito, en la cual la proporción es "divina", los seres lucirían, apropiadamente, asexuados. Diez años más tarde, toda esta sexualidad explícita se encontraba -ligeramente mitigada- en la edición impresa del Harmonices Mundi y, bajo la expresión membris sexus indicibus distinctas, se aludía al sencillo dibujo al margen. KEPLER, 1619, III: 77; 1937, vol. 6: 175; 1997: 241. 
procreación (sexual, aritmética o geométrica) puede interpretarse que -como se verá a continuación-el Creador ha dado al universo esta andrógina cualidad en forma de canto eterno y auto-regenerativo para perpetuarse a sí mismo; una suerte de sexualidad musical autosuficiente.

\subsection{El Libro V: los planetas en el pentagrama, la polifonía como modelo del cosmos y el compositor como Dios}

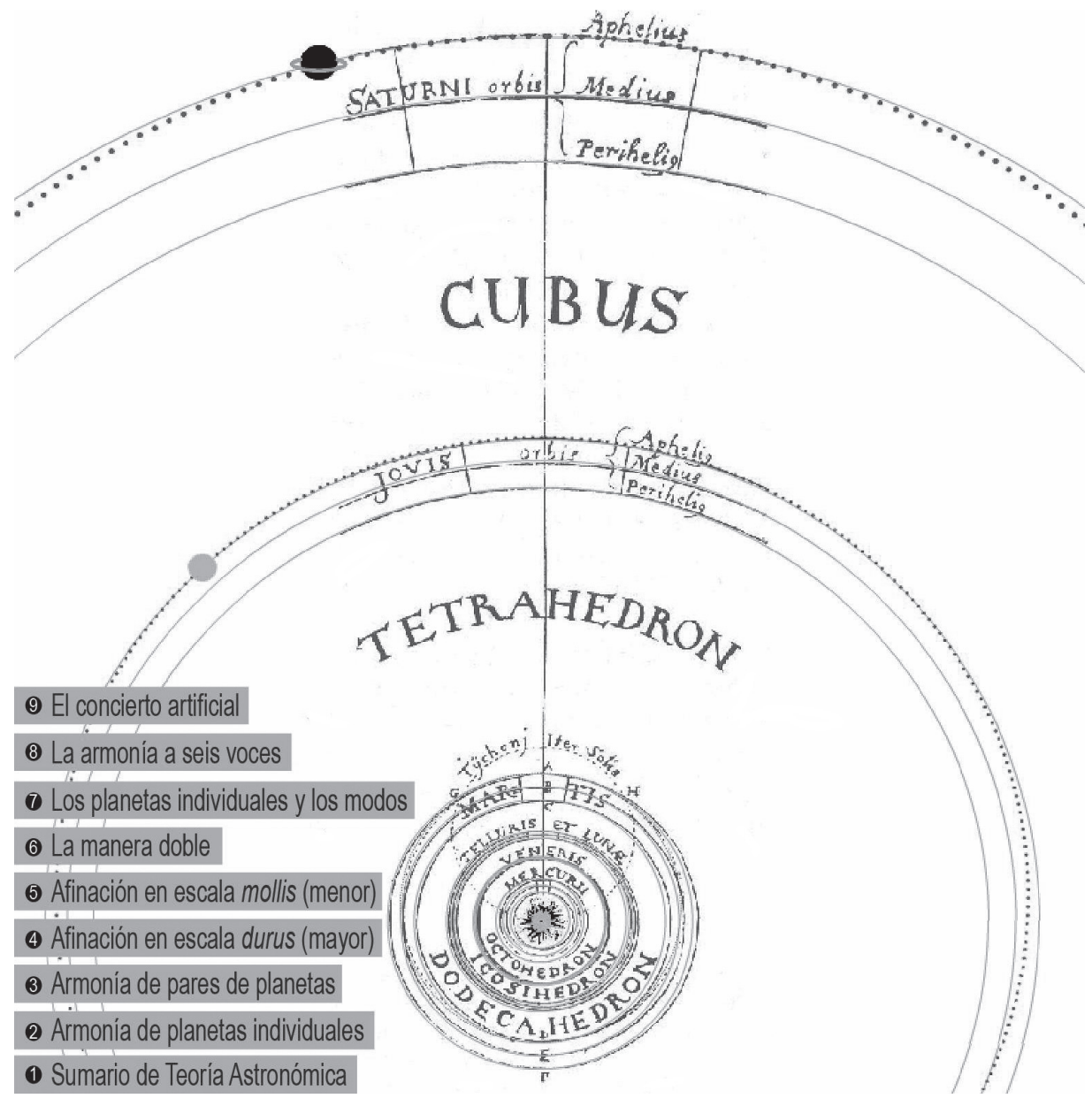

Figura 18. Esquema base y Menú de la aplicación multimedia basada en el Libro V de Kepler

Como se ha comentado al inicio de este ensayo, la aplicación multimedia expuesta en el enlace http://www.calderon-online.com/anuariomusical/kepler/harmonicemundi.html es un intento de ofrecer una imagen sonora lo más apegada posible a lo que, tal vez, Kepler imaginara en su audición interior. 
Se ruega de nuevo al lector que consulte el enlace mencionado para poder calibrar lo expuesto a lo largo del ensayo, así como en la conclusión final. A continuación se mencionará lo que puede considerarse las argumentaciones claves expuestas en el Libro V, y que conforman el menú principal de la aplicación.

$$
* * *
$$

Asumida en pleno la teoría copernicana, Kepler realizó los requeridos ardides numéricos para recalcular las observaciones de Tycho Brahe e invitar al lector a "sentarse" en el Sol para observar los planetas orbitar y "cantar" monódica y polifónicamente. ${ }^{70}$ Éste era el lugar privilegiado desde donde debía admirarse y "escucharse" el gigantesco "motete" celeste. Colocarse "mentalmente" -y también, matemática y musicalmente- en el Sol, era el principio fundamental que permitía a Kepler homologar planetas con notas musicales a través de un dato numérico dinámico: el ángulo diario recorrido por cada planeta en los llamados movimientos extremos alrededor del Sol: afelio y perihelio. ${ }^{71} \mathrm{Al}$ comparar ambos datos numéricos - velocidad en el afelio contra velocidad en el perihelio- se obtenía una proporción que para sorpresa de Kepler -y de sus lectores- coincide con algunas de las consonancias existentes. Cada consonancia fue asumida como un intervalo melódico que cada planeta "canta" y cuyo ámbito discurría desde su nota grave -al afelio-, luego ascendía a través de los grados de una escala o modo hasta su nota aguda -al perihelio- para luego descender, de nuevo, a la nota base del intervalo melódico. Y así, eternamente. Con tan sólo este dato -una proporción entre velocidades angulares-, Kepler construiría todo su edificio músico-astronómico según se muestra en la aplicación multimedia y en los apartados que a continuación se explicará y, como se dijo, coinciden con el menú de la aplicación multimedia mencionada.

Sumario de teoría astronómica. Kepler escribió un breve resumen introductorio de los fundamentos astronómicos que debían darse por sentado, a saber: la teoría copernicana, las excentricidades de las órbitas y, en especial, recordar lo expuesto en su Mysterium Cosmographicum. ${ }^{72}$

70 Tycho Brahe (*Escania, 1546; †Praga, 1601) destaca en la historia de la astronomía, tanto por el diseño de aparatos de observación y medición, como por la cantidad y precisión de los datos astronómicos y planetarios que con la ayuda de aquellos aparatos pudo acumular. En 1599 se estableció en Praga, en la corte de Rodolfo II, y fue su Matemático Imperial hasta el fin de su vida. Contrató a Kepler como asistente para calcular órbitas a partir de sus datos observacionales.

71

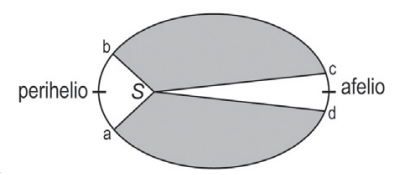

Se denomina afelio, al punto más alejado de la órbita de un planeta en torno al Sol, y en cuya velocidad angular -medida en grados y minutos de arco por día terrestre- es menor. Asimismo, se denomina perihelio al punto más cercano al Sol y donde el planeta alcanza su mayor velocidad. La Segunda Ley Planetaria de Kepler expone que, cada planeta, a lo largo de su órbita, barre áreas iguales en tiempos iguales. La imagen muestra la Ley (esquemáticamente y según dimensiones a una escala aumentada), estando el Sol en $S$ y un planeta orbitando entre los puntos $a-b$ y $c-d$. De la imagen y la certeza de la Ley, se deduce que todo planeta durante su recorrido, se encuentra acelerando y desacelerando según se acerque o aleje del Sol.

72 Estos fundamentos los colocó Kepler como condiciones a ser aceptadas para la comprensión de sus teorías. Véase KEPLER, 1619, V: 186-187; 1937, vol. 6: 297-299; 1997: 405-406. Véase, supra Nota 48, la referencia bibliográfica al Mysterium Cosmographicum y detalles para su lectura en versión digitalizada. 

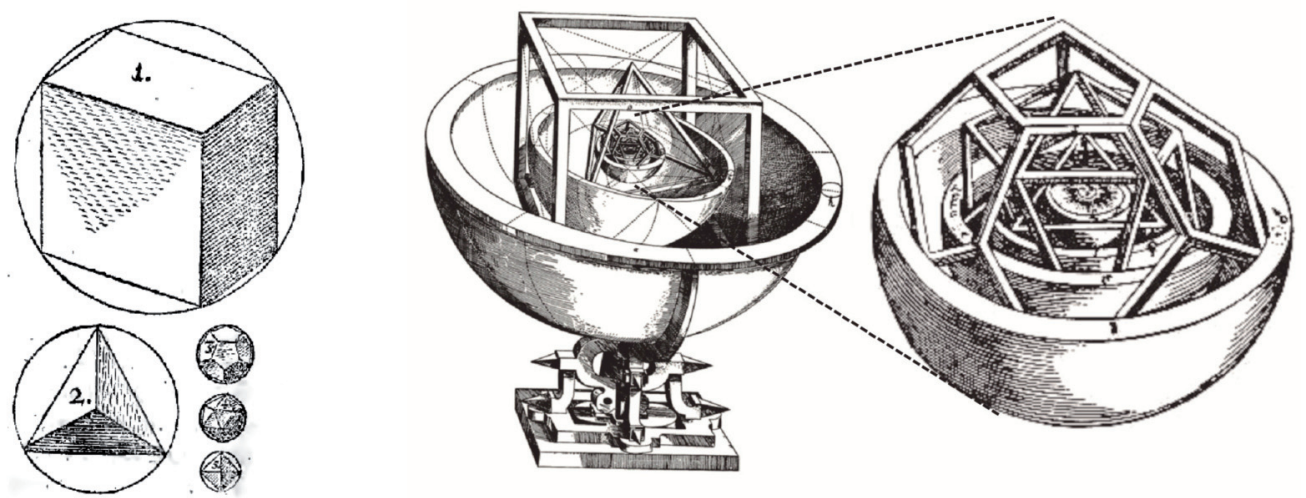

Figura 19. A la izquierda, los sólidos platónicos y los círculos que los circunscriben en KEPLER, 1619, V: 180; al centro, modelo del cosmos según el Mysterium Cosmographicum y detalle, a la derecha, de la esfera interior, con las órbitas de Marte, la Tierra Venus, Mercurio y el Sol en KEPLER,

1621: $24-25$

En el modelo de la figura anterior, se observan los sólidos platónicos encajados uno dentro de otro como explicación geométrica causal de que existieran seis, y sólo seis planetas, y a ciertas distancias determinadas al Sol. Según Kepler la secuencia de este anidamiento de sólidos y las esferas que los contenían, poseían diámetros que coincidían (aunque Kepler nunca pudiera demostrarlo de manera exacta), con las supuestas órbitas circulares de los planetas. A pesar de la inexactitud de aquél primer modelo, Kepler nunca renunció a él, es decir, ese "esqueleto" estático del cosmos, ahora, en su Harmonices Mundi, se habría convertido en complemento de un nuevo modelo dinámico que estaba basado en la excentricidad de las órbitas, el movimiento con aceleraciones y desaceleraciones, y que quedaba justificado por los intervalos musicales de la armonía.

Armonía de planetas individuales. Como ya se dijo, dado entonces el dato numérico de las velocidades angulares diarias de un planeta -en su afelio y perihelio- al colocarlas en forma de razón o proporción, se asumía este nuevo dato como un intervalo melódico recorrido por el planeta. Este tipo de armonía, en forma de línea melódica ascendente y descendente, le complace, pero por ser monódica fue asociada con el canto simple "quae sola Veteribus fuit cognita." 73

73 “El único conocido por los antiguos.” KEPLER, 1619, V: 201; 1937, vol. 6: 316; 1997: 430. 


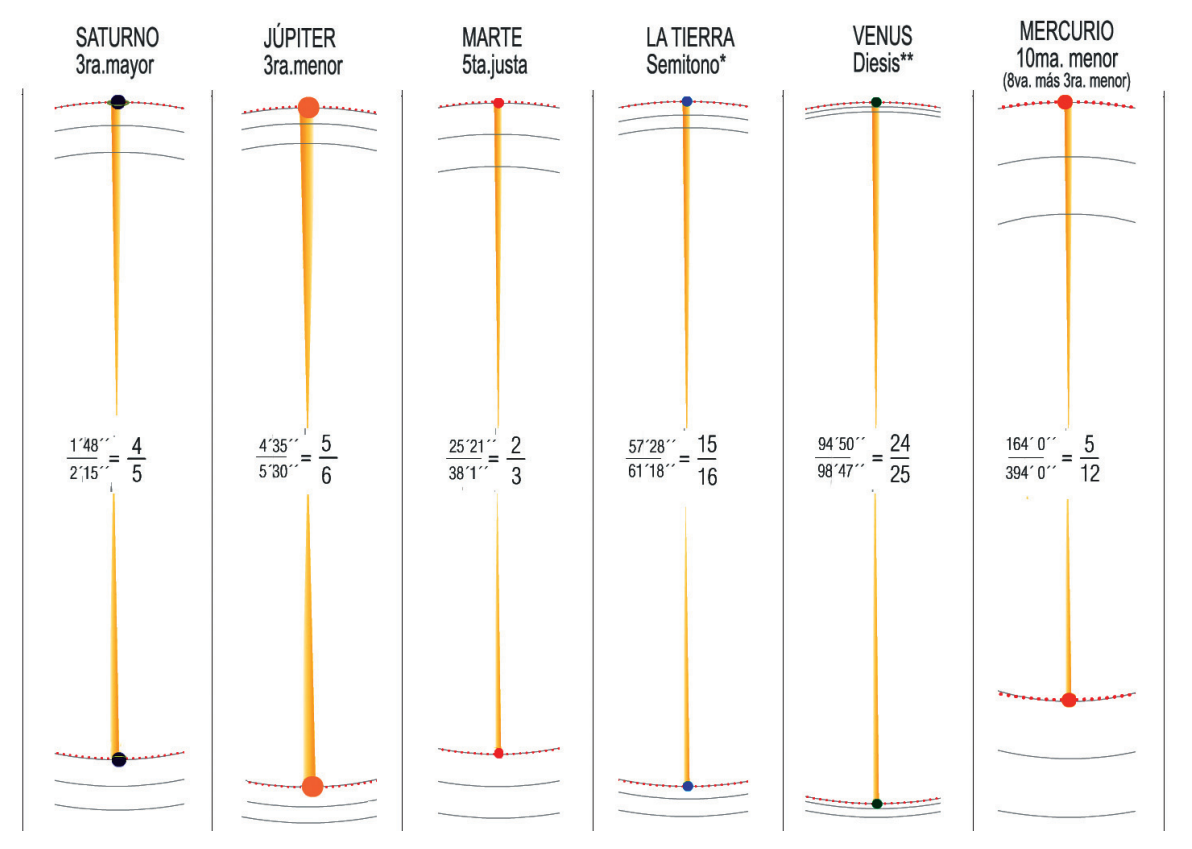

Figura 20. Proporciones armónicas de los planetas individuales. ${ }^{74}$

Armonía de pares de planetas. Al comparar los movimientos extremos, no de un único planeta sino de planetas diferentes, Kepler halló también proporciones armónicas. Este hallazgo le causó la mayor sorpresa y placer, a la par que lo estimulaba a la consideración del cosmos como un todo "polifónico". Kepler expresaba aquí el salto cualitativo de la monodia antigua, hacia la polifonía de los modernos, y cuyo ejemplo supremo era la música de Orlando di Lasso. En otras palabras, el imaginar que cada planeta "cantase" una melodía, era algo que había sido considerado desde la antigüedad como una posibilidad que rozaba, incluso, con la simbología; ahora, en el siglo XVII, la visión polifónica de los varios planetas -ajustada a las reglas del contrapunto, la afinación justa y los datos numéricos de Tycho Brahe- eran una afirmación filosófica moderna y de mucho mayor calado.

74 *El semitono de proporción 15:16 lo había obtenido Kepler como la diferencia entre la 4ta. justa de proporción 3:4 y la 3ra. mayor justa de proporción 4:5. **La proporción 24:25, que Kepler denominaba diesis, la había obtenido de la diferencia entre la 3ra. mayor y la 3ra. menor, ambas justas y de proporción 4:5 y 5:6, respectivamente. En la antigüedad, los términos diesis ("pasar a través") y limma ("resto"), fueron utilizados, indistintamente, para referirse a diversos intervalos de pequeño tamaño. Kepler aclaraba que la utilización del término diesis para la proporción 24:25, no coincidía con aquella voce veterii (voz de los antigüos) con la cual se denominaba a la diesis o limma pitagórica, cuya proporción era 243:256 (obtenida de la diferencia entre la 4ta. justa de proporción 3:4, menos la 3ra. mayor pitagórica o ditono, de proporción 64:81). La utilización kepleriana del término diesis quedaba justificada como un término genérico para lo que él consideraba un intervalo imperfecto en origen y tamaño, y por no estar al servicio de la creación de melodías. Véase KEPLER, 1619, III: 38; 1937, vol. 6: 131; 1997: 180. 


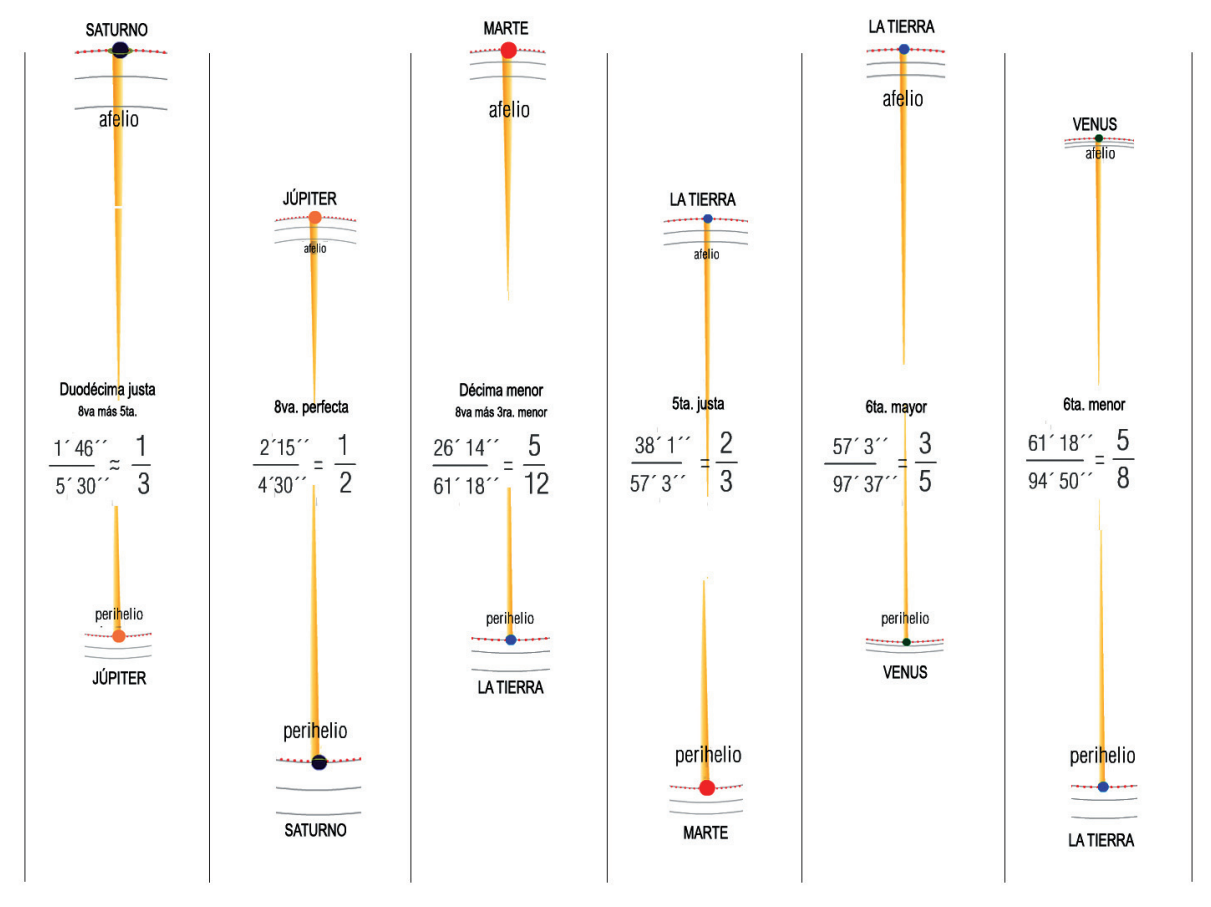

Figura 21. Armonía de los pares Saturno-Júpiter; Marte-La Tierra; La Tierra-Venus. Nótese la alternancia entre 6ta. mayor y menor que, a manera de dúo, "entonan” La Tierra y Venus

Afinación en escala durus y mollis. Para confirmar lo anterior y demostrar que todo el universo encajaba en su teoría musical, Kepler reorganizó en una octava simple todos los movimientos extremos de los planetas y demostró que todos se ajustaban a una escala, sea mayor o menor. Para ello, tomó como base el afelio de Saturno -el planeta más alejado en su punto, igualmente, más alejado y lento- y lo ubicó como la nota $\mathrm{Sol}(\mathrm{G})$ más grave. El resto de planetas se posicionaba de la siguiente manera. 


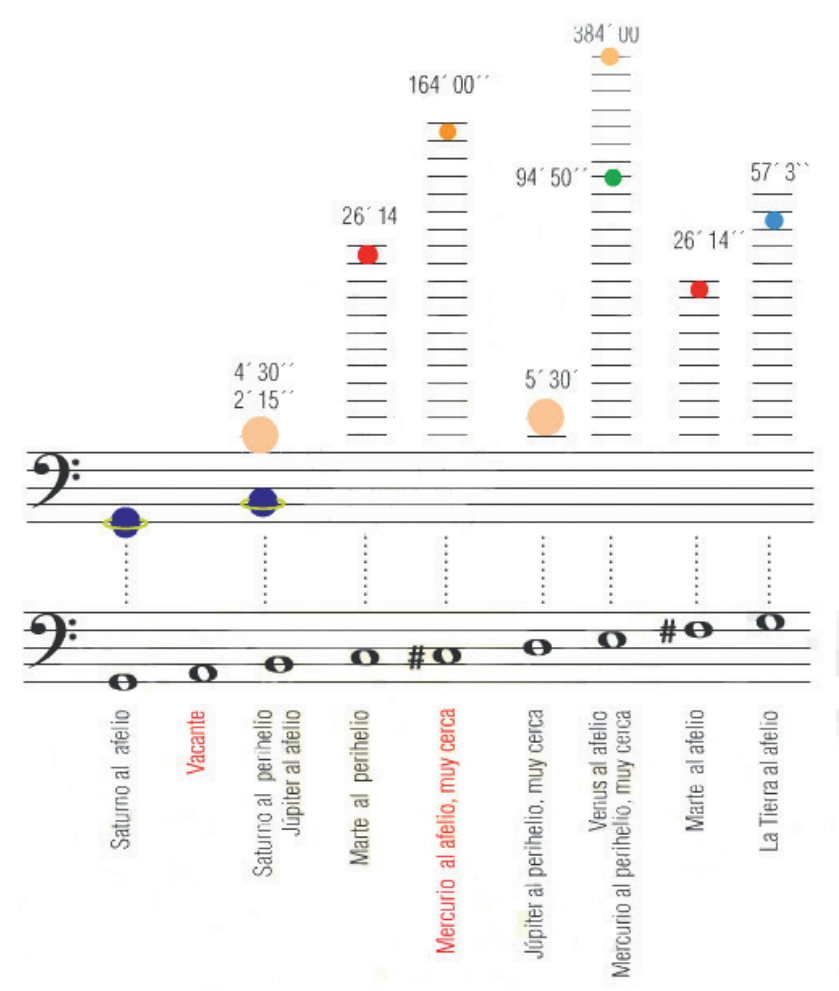

Figura 22. Correspondencia entre planetas y notas musicales en escala durus

En la figura, el pentagrama superior muestra la correspondencia exacta entre la velocidad angular de cada planeta y el registro exacto donde correspondería, como nota musical, según su proporción armónica. En el pentagrama inferior se muestra la escala durus que se produce, una vez que estos planetas-notas han sido simplificados por octavas, haciéndolos encajar en una sola octava. Nótese que no están, ni el perihelio de Venus, ni el de La Tierra, y que el lugar Vacante, Kepler lo ha rellenado con la nota adecuada a la escala que inicia en Sol. ${ }^{75}$

Hay que hacer notar que una vez colocado cualquier planeta en el pentagrama, éste quedaba a merced para cualquier consideración propia de la música. La primera operación "musical” que realizó Kepler al "astronómico" planeta fue desplazarlo en octavas, simplificando o doblando su altura hasta hacer encajar así a todas las notas - es decir, todos los planetas- en el ámbito de una octava (véase $\boldsymbol{F} \boldsymbol{i}$ gura 22). No obstante que para Kepler la octava era por esencia simple, perfecta e idéntica, puede con-

75 Véase en la aplicación multimedia el desarrollo de la propuesta para la escala mollis. 
siderarse que este acto de simplificar o doblar a la octava, violentaba toda la observación astronómica realizada. Estaba claro que descender o elevar una nota en una octava era una operación estrictamente musical que permitía considerar a los sonidos como "equivalentes", dada su condición de consonancia perfecta; pero también resulta claro que esta operación equivale, astronómicamente hablando, a desacelerar o acelerar un planeta, lo que haría saltar en pedazos todo el esquema kepleriano. Es decir, Kepler deseaba que los seis planetas encajaran en el ámbito de una octava, pero ¿qué es una octava astronómicamente hablando?, ¿es posible hablar de ello? También es claro que desacelerar a la mitad o duplicar la velocidad angular de un planeta supondría modificar los períodos de las órbitas y violar la misma Tercera Ley Planetaria que Kepler enunciara. En resumen, en el marco de lo expuesto por Kepler, una operación musical como ésta no sería del todo asimilable en su concepción astronómica, pero es tal el convencimiento de que ambas disciplinas son homologables a través del arquetipo geométrico, que este tipo de operación no le inmuta.

La manera doble. Las operaciones anteriores producían dos maneras de estructuración o "afinación" del universo: una durus, cuando la nota más grave del sistema viniera dada por el afelio de Saturno, y una mollis si viniera dada por su perihelio.
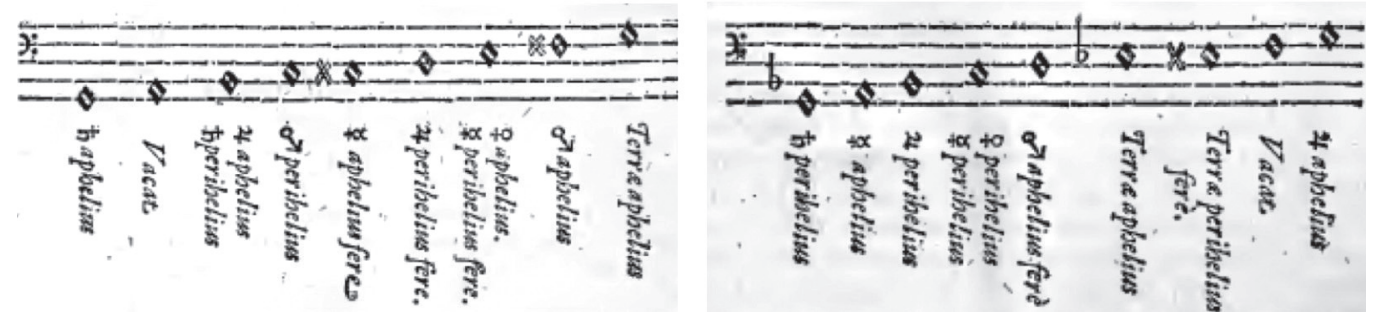

Figura 23. La duplici via o doble manera de presentarse en el cielo los tipos de melodía durus y mollis, la escala musical y el sistema de la octava

Esta "doble manera", tal como se ha comentado en el Apartado 3.2. poseía una lectura simbólicosexual que Kepler expresaba de manera explícita. En este sentido, esos dos pentagramas -escalas durus y mollis- pueden ser interpretados como los representantes de género del universo.

Los planetas individuales y los modos. Atendiendo siempre al intervalo musical que recorría el planeta según sus movimientos extremos de afelio y perihelio, Kepler asignó a cada planeta uno o más modos según su propia teoría musical. ${ }^{76}$ Así, con la célebre ilustración del grupo de pentagramas que se colocara al inicio de este ensayo, Kepler demostraba que la música eclesiástica, no sólo era un subconjunto de su teoría musical general, sino que también, podía expresarse en los cielos de la siguiente manera:

76 Véase supra, en el Apartado 3.2 al respecto de la construcción de los Modos Eclesiásticos. 

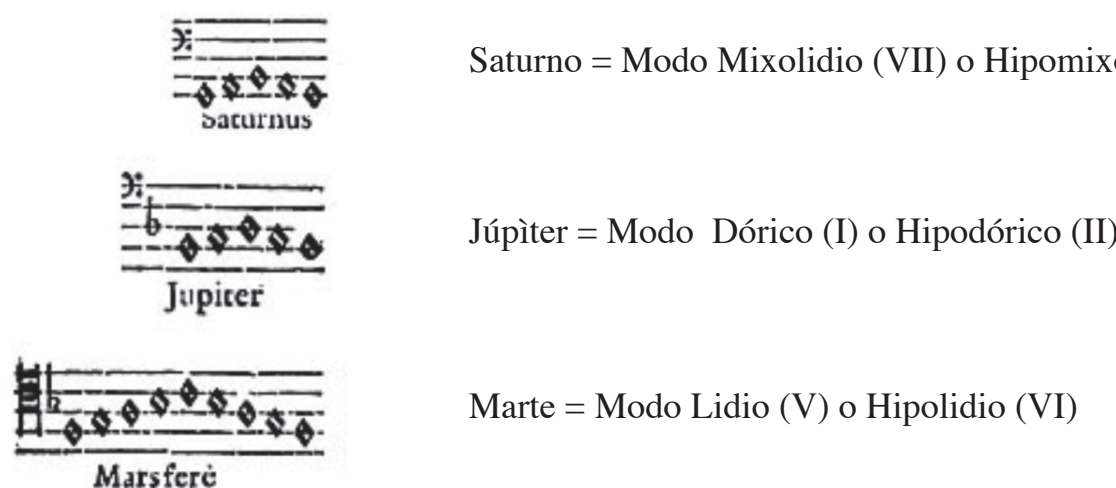

Marte $=$ Modo Lidio $(\mathrm{V})$ o Hipolidio $(\mathrm{VI})$

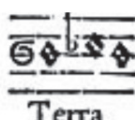

La Tierra $=$ Modo Frigio $\left(\right.$ III) o Hipofrigio $(\text { IV })^{77}$

Terra

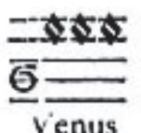

Venus $=$ Modo Frigio (III) o Hipofrigio (IV)

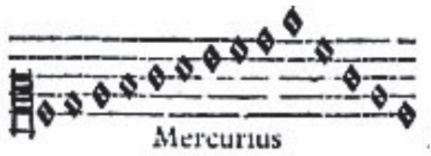

Mercurio = Cualquiera de los ocho Modos Eclesiásticos

Kepler reconocía que esta adjudicación no era necesariamente la única, e invitaba a probar nuevas configuraciones al escribir:

Liberum autem erit Harmonistae, sententiam depromere suam: quem quisque planeta Modum exprimat propiùs, extremis hîc ipsi assignatis. ${ }^{78}$

77 Dado que La Tierra solo cantaba un semitono, Kepler convino en asignarle los modos III o IV (que tenían como nota finalis o fundamental el Mi, seguido del Fa). No obstante, en la ilustración colocó un modo "transportado" a Sol (seguido del La bemol) A pesar de esto, Kepler insistía en comentar su curiosa "deducción” sobre la naturaleza de la melodía Mi-Fa-Mi que entonaba La Tierra: "Tellus canit MI FA MI ut vel ex syllaba conjicias, in hoc nostro domicilio MIseriam et FAmem obtinere." ("La Tierra canta MI FA MI y de estas sílabas se infiere que, en nuestro hogar, obtenemos MIseria y HAmbre"). Esta nota -al margen de página y no exenta de cierto humor saturnino- puede interpretarse como testamento del aciago período que le tocara vivir durante la Guerra de los Treinta Años. Véase la nota al margen en el Capítulo VI del Libro V en KEPLER, 1619, V: 207; 1937, vol. 6: 322; 1997: 440.

78 "Ahora, queda abierto a cualquier músico llegar a sus propias conclusiones sobre qué modo se expresa mejor para cada planeta, una vez que los extremos han sido asignados para él.” KEPLER, 1619, V: 207; 1937, vol. 6: 322; 1997: 440. Kepler es consciente de que los planetas discurren, realmente, a través de un cambio de nota continuo y potencialmente infinitesimal -no a saltos, sino en una suerte de ulular ascendente y descendente- pero aclaraba que, musicalmente, solo podía expresarlo a través de notas intermedias - grados conjuntos de cada modo seleccionado, salvo el caso de Mercurio, en el que incorporó saltos de 3ras y 4tas-. En este caso de Mercurio, tal vez problemas de composición tipográfica no permitieron desplegar el completo ascenso y 
Lo que primero salta a la vista es la diversidad de modos asignados a los planetas. ¿Estaría Kepler creando -o invitando a crear- un universo polimodal y/o politonal cuyo anacronismo es del todo evidente? Seguramente no, puesto que Kepler había sido enfático en afirmar que cada planeta entonaba un cantus simplicis a la manera de los "antiguos", que no conocían la polifonía de los modernos. Por ello, Kepler no invitaba -y sería erróneo hacerlo- a imaginar la simultaneidad sonora de todo este grupo de pentagramas, ni mucho menos pensaba en especie alguna de "polimodalidad" o "politonalidad" como esquemas organizadores de su polifonía. La insistencia en colocar este grupo de pentagramas como ejemplo o epítome de una polifonía celeste, no se corresponde con las argumentaciones keplerianas pues, en este caso, cada pentagrama correspondía a un planeta individual en un modo individual. No había polifonía allí, sino tan sólo una adjudicación modal a melodías individuales.79

Las armonías a seis voces. "Sequimini Musici moderni" ("Síganme, músicos modernos”) era la invitación que hacía Kepler a contemplar un cosmos armónico que se expandía a través de siete octavas. Este concepto: Concentus harmonicus, suponía la existencia de dos, tres, cuatro o más melodías coherentes, todas de la misma clase, o de modos idénticos o similares

[...] omnes ejusdem Generis, ejusdemque aut, cognato rum Modorum, sic simul incedentes; ut concordantias aut meras, aut brevissimo Concinnarum dissonantiarum interpunctu fermentatas faciant; non eas tamen perpetuo tenore identicas, nec easdem deinceps; sed ipsa successionum alternatione ad delectationem variatas. ${ }^{80}$

Como se nota, es ésta una definición estrictamente polifónica y no ofrece consideraciones algunas sobre la noción moderna de "acorde" que algunos historiadores y musicólogos han utilizado para evaluar aspectos del Harmonices Mundi. Por un lado, Stephenson habla de "acordes universales" y, por otro, Walker utiliza términos como 'resolución del acorde' o 'cadenza' para el análisis de las gigantescas armonías y, para manifestar su desconcierto ante acordes tipo 6/4 o de "cuarta contra el bajo". 81

descenso, pero puede perfectamente interpretarse que deberían ser iguales, tal como se ha realizado en la aplicación multimedia (dejando claramente indicada la propuesta original de Kepler).

79 Es cierto que en la polifonía de la época, -conforme las líneas melódicas se multiplicaban, se hacían más complejas y se superponían- se hacía extremadamente difícil mantener todas las voces en un único y estricto modo, tal como hiciera la monodía simple y la temprana polifonía a dos voces, a intervalos de cuarta o quinta. Sin embargo, los compositores lograban mantener su apego a un único modo a través de la voz del tenor, que se mantenía en un modo reconocible mientras el resto de voces procuraba, siguiendo las leyes de la armonía, entrar en consonancia con éste. Pero nada de esto estaba expuesto ni considerado en la teoría de Kepler.

80 " $[\ldots]$ t... todas del mismo género, o del mismo modo o su relativo, que al ser ejecutadas al mismo tiempo, de tal manera haya consonancias puras entre ellas y se permitan breves disonancias melódicas; incluso si no mantienen un idéntico curso, ni siendo las mismas, sino que, difieren en una constante alternancia de sucesos que nos da deleite." KEPLER, 1619, III: 80; 1937, vol. 6: 179-180; 1997: 247. Como se nota en la cita, el mismo Kepler hablaba de armonía de voces conjuntas cuando éstas se encuentran en el mismo modo o relacionados (ej. dórico e hipodórico, lidio e hipolidio, etc.) lo que confirma las observaciones al respecto de la imposible politonalidad o polimodalidad kepleriana y, es por ello, que los célebres pentagramas llevan a un equívoco si son asociados como una polifonía en pleno.

81 Véase STEPHENSON, 1994: 173 y también, WALKER, 1979: 57-62. 


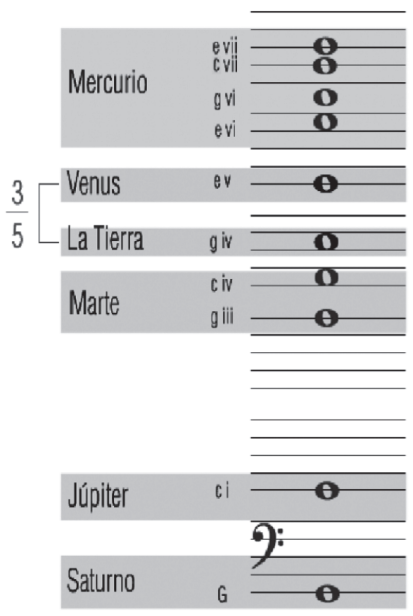

Figura 24. Armonía a seis voces que incluye: Saturno en la nota Sol, 6ta. mayor entre Venus y La Tierra incorporando al Do en la armonía

Aunque en ningún momento Kepler hacía referencia a la idea de acorde, no debe negarse la capacidad explicativa que nuestras teorías musicales contemporáneas, puedan arrojar al Harmonices Mundi. Sin embargo, puede afirmarse que Kepler mantuvo un pensamiento "polifónico" y, ni la noción de "acorde", ni mucho menos la de "inversión de acorde", formaban parte (ni podían formarlo) de sus especulaciones ni de su instrumental teórico. Su pensamiento polifónico se resume en que cada planeta discurre melódicamente y, que en momentos muy significativos, la simultaneidad de movimientos (tanto sonora como astronómica) produce un encuentro de intervalos o "armonías" que están de acuerdo con las reglas expuestas por el propio Kepler en su Libro III.

Estos momentos significativos de la armonía a seis voces se producen muy raramente, puesto que para que coincidan de manera consonante en un mismo momento los movimientos extremos de afelio y/o perihelio de varios planetas (especialmente los más lentos) sería necesario esperar miles de años. Kepler lo explicaba así:

Quòd si tres in unam Harmoniam conspirate debeant: multae quidem vices sunt exspectandae; multae tamen Harmoniae sunt; ut ita tantò faciliùs contingant, dum vicinam suam proxima quaeque excipit: videnturque inter Martem, Tellurem et Mercurium, triplices contingere saepiusculè, Quatuor verò planetarum Harmoniae, jam incipiunt spargi in saecula: quinque Planetarum in Myriadas annorum. ${ }^{82}$

82 "No obstante, hay muchas armonías que ocurren fácilmente cuando todos los planetas cercanos atrapan a sus vecinos; mientras que las armonías triples, entre Marte, la Tierra, Mercurio, suelen ocurrir en raras ocasiones. Las armonías de cuatro planetas se dispersan a lo largo de siglos, y aquellas de cinco planetas, durante miríadas de años." KEPLER, 1619, V: 208; 1937, vol. 6: 324; 1997: 441. 
El momento más significativo, por supuesto, será aquel en el que todos los seis planetas coincidan en una configuración armónica de afelios y perihelios; pero Kepler dudaba si eso hubiera ocurrido una vez o dos. Ante esto, enunciaba:

Quòd si unica sola contingere posset Harmonia sextuplex, aut inter plures unica insignis; ea proculdubio pro charactere Creationis haberi posset. ${ }^{83}$

El mundo se inició pues, -en esta "versión sonora del Big Bang”-, con una gigantesca campanada armónica.

El concierto artificial. El objetivo final se alcanzaba cuando podía imaginarse al cosmos como un conjunto polifónico que "vocaliza" sus melodías según las tesituras que Kepler adjudicara a los planetas, a saber, Bajo: Saturno y Júpiter; Tenor: Marte; Contralto: Tierra y Venus; Soprano: Mercurio ${ }^{84}$ He aquí el momento culminante en que el cosmos debía ser entendido y percibido como un gigantesco y perenne motete polifónico

$[\ldots]$ (rationalis no vocalis), per disonantes tensiones, veluti quasdam Syncopationes vel Cadentias $[\ldots] .{ }^{85}$

Nótese que Kepler insistía en lo "mental" de todo esto. No obstante, debe reconocerse que esta teoría, concebida desde lo armónico y musical, no se reducía a una mera y "sorda" actividad racional; recuérdese que el propio Kepler ya había reclamado, para este cosmos, un "aire” que satisficiera, sonoramente, lo sensual. ${ }^{86}$

Ahora sí podían cerrarse todos los anteriores argumentos en uno solo, que incluía, al creador, al hombre y su canto, a la antigua monodía y la moderna polifonía, al tiempo terrenal y al tiempo eterno. Era la experiencia estética suprema, en la cual una hora de esta "música" podía convertirse en una analogía de la eternidad del universo, y el compositor en modelo de su creador divino:

[...] ut mirum amplius non sit, tandem inventam esse ab Homine, Creatoris sui Simiâ, rationem canendi per concentum, ignotam veteribus; ut scilicet totius Temporis mundani perpetuitatem in brevi aliqua Horae parte, per artificiosam plurium vocum symphoniam luderet, Deique Opficis complacentiam in operibus suis, suavissimo sensu voluptatis, ex hac Dei imitatrice Musicâ perceptae, quadamtenus degustaret. ${ }^{87}$

83 "Pero si alguna armonía séxtuple simple ocurre, sería una excepcional entre muchas, sin duda debería ser entendida como la de la Creación.” KEPLER, 1619, V: 209; 1937, vol. 6: 324; 1997: 442.

84 En la aplicación multimedia, se ha simulado esta vocalización manteniendo las melodías de cada planeta en una única tonalidad, sea durus o mollis, tal como Kepler ha sugerido y según sus exactos datos numéricos. Las notas intermedias que recorre cada planeta - con sus bemoles o sostenidos-, son aquellas propias del sistema de afinación utilizado y provienen de la naturaleza propia de la tonalidad y del intervalo que posee cada planeta según su afelio y perihelio. Al hacer esto se acepta -tardíamente, con seguridad- la invitación de Kepler a ofrecer un esquema según conclusiones propias. Véase supra, Nota 78.

85 “[...] (racional, no vocal), por tensiones disonantes, como ciertas Síncopas y Cadencias [...]”. KEPLER, 1619, V: 209; 1937, vol. 6: $328 ; 1997: 446$.

86 Véase Nota 46.

87 “Así, no debe sorprendernos ya más, que el Hombre, imitando a su creador, haya encontrado al fin un método de cantar en armonía que era desconocido para los antiguos, de manera que puede ejecutar, por decirlo así, la perpetuidad de todo el tiempo 
Así, este texto, que podría leerse como una expresión poética o una exaltación mística, debe entenderse como un alegato epistemológico que hinca sus raíces en una experiencia estética que ha sido elevada al rango de teoría de conocimiento. ¿Hay algo lógicamente incorrecto en esta operación? Aunque se haya llamado la atención en algunos aspectos que sorprenden, dado el convencimiento de Kepler en homologar las disciplinas de la música y la astronomía, la estructura lógica basada en la geometría y en la idea de un arquetipo común, otorga a los argumentos una verdad por coherencia invulnerable. Pero, para poder asumir todo ello, es necesario estar convencido que,

\section{[...] Deus nihil sine Geometrica pulchritudine constituerit $[\ldots]{ }^{88}$}

Esta es la gran hipótesis, y como se ve, posee el concepto de belleza en su seno y a lo divino como gestor. Lo que ha hecho Kepler es convencerse de que esta belleza podía expresarse de variadas maneras y no solo en las platónicas figuras geométricas, sino en los sonidos de un monocordio, en el canto humano, en la obra de un compositor como Orlando di Lasso y, por supuesto, en el elíptico orbitar de los planetas.

Por todo lo expuesto, la más interesante de todas estas intersecciones, traslaciones e intercambios entre astronomía y música -y ahora, dentro de un marco divino y teológico- la proponía Kepler cuando clamaba por algún músico moderno que valiéndose de textos sagrados afrontara la tarea de componer una obra armonizando seis voces y que pudiera representar, en su totalidad a la Naturaleza. Escribía Kepler -tímidamente- en una acotación al margen:

Anne flagitium fecero, si à singulis hujus aetatis Componistis artificiosam aliquam Motetam pro hoc Elogio exigam? Textum huc aptum Psaltes Regius, caeterique Sacri libri suppeditare poterunt. Verum heus vos, in coelo plures quam sex non concordant. ${ }^{89}$

¿Está pidiendo Kepler una bella obra de arte, una correcta e ingeniosa interpretación musical de los cielos, o una versión sonora de las teorías que ha elaborado pacientemente en los Libros III y V? Cuando Kepler solicitaba este motete -no sin cierta culpa o temor- parecía reconocer la aridez sonora de sus teorías y, es en ese momento, cuando clamaba por el arte de un compositor individual de su época. De hecho, si el lector ha podido escuchar -en la aplicación multimedia- o imaginar cómo podría sonar toda aquella "música celestial” que, según Kepler, "producen” los planetas, puede y debe, reconocer que es compleja,

cósmico en una breve fracción de una hora, por medio del concierto artificial de varias voces y saborear, hasta cierto punto, la satisfacción de Dios su Hacedor en Sus obras, a través de esta deliciosa sensación de placer que se siente en esta imitadora de Dios, la Música.” KEPLER, 1619, V: 213; 1937, vol. 6: 328; 1997: 446-448.

88 “Dios no hace nada sin una belleza geométrica [...]."KEPLER, 1619, V: 194; 1937, vol. 6: 308; 1997: 419.

89 “Estaría cometiendo un crimen si pidiera a un compositor de una generación un ingenioso motete, en lugar de este elogio? Hay textos aptos, el Psalterio Real y otros libros sacros pueden suplirlos. Pero toma nota: en el cielo no más de seis voces hacen armonía." KEPLER, 1619, V: 208; 1937, vol. 6: 323; 1997: 441. Nótese que Kepler insiste en un motete a seis voces, dejando la Luna fuera del discurso musical. Para Kepler la Luna canturrea su monodía, de manera independiente, cunis assidens, es decir como si arrullara a la Tierra con una canción de cuna. Ibid. 
variada, curiosa e interesante, pero nunca tan hermosa ni seductora como cualquiera de los tres motetes de Lasso que ha mencionado en su obra. ${ }^{90}$

Huelga agregar que esto último, como toda disputa estética, es discutible. Pero sí es posible preguntarse: ¿Era entonces este clamor por una obra musical, una solicitud póstuma a Orlando di Lasso, el único compositor que Kepler citara a lo largo del Harmonices Mundi y que había muerto hace más de una década? Fuera este o no el caso, Kepler podría obligar a invertir todo el planteamiento principal de este ensayo, pues esta geometría que ahora demandaba un motete, sería la muestra de que, también ahora, la formulación científica clamaba por una experiencia estética.

\section{CONCLUSIONES: LA POLIFONÍA COMO CONTEXTO VERDADERO}

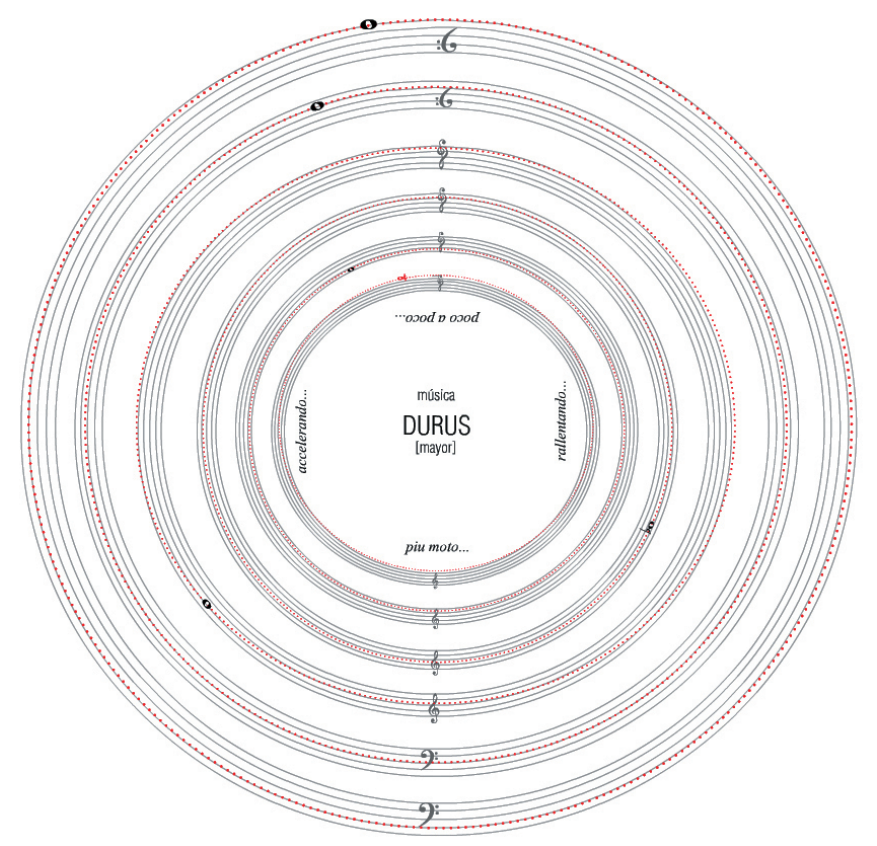

Figura 25. Interpretación gráfica, como perpetuo motete polifónico a seis voces, de la música durus, según las teorías de Kepler

Es evidente que de haber escuchado un motete de Orlando di Lasso, no pudo deducirse una verdad científica como la Tercera Ley Planetaria de Kepler; y aunque el filósofo no nos haya dejado la pista exacta

90 Véase supra, Nota 31. 
de cómo llegó a descubrirla, sería erróneo pensar que no ha nacido bajo el amparo de las proporciones armónicas que fueron afanosamente buscadas, primero en los períodos de los planetas, luego en sus tamaños y volúmenes, de nuevo infructuosamente en las distancias solares y finalmente, con éxito, entre las velocidades angulares medidas en los movimientos extremos de los planetas, tomando al Sol como referencia. ${ }^{91}$

Esta relación entre período y distancia también había sido buscada afanosamente desde el Mysterium Cosmographicum y como es aceptado hoy día, es uno de los mayores logros científicos de Kepler y de la astronomía moderna. Pero no era difícil aceptar que si la distancia al Sol de alguna manera "gobernaba" las velocidades, entonces el Sol podía ser: "fonte Motus omnium Planetarum". ${ }^{92}$ Así entonces, el Harmonices Mundi confirmaba la posición privilegiada del Sol como asiento de la virtud motriz y seu Regiam (trono real) desde donde debía apreciarse la armonía de los planetas. ${ }^{93}$ De aquí en adelante, los datos se organizaron para evidenciar las proporciones armónicas como estructura de un gran sistema en movimiento que, al igual que las voces de un motete, despliegan una inusual belleza adjudicable solo al Dios geómetra-astrónomo-músico. Si bien las proporciones armónicas no son las causas físicas del movimiento, sí son las razones de su diseño y, si bien Lasso no es Dios, lo imita, al menos, muy bien.

Lo característico de este pensamiento, y que lo desliga de todas las tradiciones a este respecto, es que esta armonía no era estática sino que poseía la misma dinámica que la polifonía de sus músicos contemporáneos. El planeta no se movía “debido" a la armonía, pero al moverse, su velocidad no podía ser otra sino aquella que encajara con las proporciones armónicas y la música moderna figurada. Visto así, la armonía era el plan de diseño y la polifonía contemporánea el correlato histórico que la refrendaba. Si bien la belleza que crea Dios es eterna, Lasso la ha logrado recrear en un momento histórico exacto. El papel de Kepler ha sido evidenciarlo.

Una lectura atenta del Harmonices Mundi ha permitido constatar que Kepler realizaba constantemente referencias a la "música moderna" como elemento que justificaba la validez de sus razonamientos. A lo largo de los cinco libros, la diferenciación antiguo-moderno se convertía en la clave para comprender el porqué Kepler podía presentar su esquema armónico-astronómico basado en los aportes de la armonía de finales del siglo XVI. Estos aportes consistían en las terceras y sextas como intervalos consonantes que ampliaban el espectro melódico compositivo, y la introducción de nuevos motivos rítmicos y melódicos que dotaban a la música de mayor complejidad. Todo esto, a su vez, habría ampliado los horizontes expresivos para ofrecer al compositor un espacio donde su inventiva fluiría con nuevos y variados motivos y,

91 El mecanismo exacto del descubrimiento de la Tercera Ley Planetaria se desconoce; mas, sin embargo, el día exacto y el alborozo que causaron, sí está documentado por el propio Kepler: el 8 de marzo de 1618 en un primer errado intento de cálculo y el 15 de mayo con una nueva aproximación que disipó Mentis meae tenebras ["las sombras de mi mente"]. KEPLER, 1619, V: 189; 1937, vol. 6: 302; 1997: 411-412.

92 “[...] fuente de todos los movimientos de los planetas.” KEPLER, 1619, V: 195; 1937, vol. 6: 312; 1997: 424.

93 Kepler preguntaba, al final del Harmonices Mundi, en su Epilogus de Sole, Conjecturalis ("Epílogo Conjetural sobre el Sol") qué mente o intelecto debería habitar en el Sol para el cual las armonías son su objeto. Kepler conjeturaba que, por ventura, algunas creaturae inteligentes, Naturae diversae ab Humana, ("criaturas inteligentes de naturaleza diversa a la humana"), habitan o podrían habitar un globo así como el Sol. Kepler exclamaba, desesperado: "Cui usui hic apparatus, si globus vacus? An non vel sensus ipsi exclamant, ígnea hic habitare corpora, Mentium simplicium capacia [...]?” (“¿Para qué serviría este aparato, si es un globo vacío? ¿No claman los propios sentidos por unos cuerpos ígneos que lo habiten, capaces de una mente simple [...]?”) KEPLER, 1619, V: 248; 1937, vol. 6: 368; 1997: 497. 
hacia finales del Renacimiento, adquirió un carácter comunicativo muy marcado, al entrar en contacto con los teóricos alemanes y los músicos que habían dirigido sus esfuerzos hacia la capacidad de "mover los afectos" que poseía la música. Finalmente, los teóricos alemanes -bajo el influjo de la Reforma-lograron darle forma a una teoría que permitía encontrar la devoción por el texto sagrado, junto a la capacidad de persuadir a sus oyentes, y todo, en el marco de la justificación matemática. En otras palabras, el tránsito del siglo XVI al XVII vivió con intensidad esta transición de la música como "número" a la música como "figura retórica", es decir, el nacimiento de la Musica Poetica. ${ }^{94}$

Además de estos aportes -expresividad y retórica-, es necesario insistir en el sentido teológico de la música. Asociado a la Musica Poetica y en el marco de la cultura protestante, la oración era siempre "oración en música", "sermón en sonidos". Allí donde la clasificación musical tripartita de Boecio (mundana, humana e instrumentalis) no contemplaba un Dios, sino tan sólo a un Cosmos autosuficiente en su ordenamiento, la Reforma protestante otorgó a la música un carácter divino y un ethos músico-teológico basado en la ciencia especulativa y las proporciones numéricas. Todo maestro de escuela debía ser dotado en música, y a través de las escuelas este proyecto cultural iniciado por Lutero se insufló tanto en el pueblo llano como en sus filósofos y teólogos. Lutero siempre mantuvo que los profetas habían unido su teología no a las matemáticas, pero sí a la música; diciéndonos la verdad a través de salmos e himnos. Kepler, como buen luterano, siguió este mandato e hizo lo que los profetas no habían logrado, es decir, unir en un todo, la teología con la música, y también, con la astronomía, la geometría y la aritmética.

Así entonces, el esquema de aportes de la polifonía contemporánea unido al sentido retórico y teológico que le otorga la Reforma protestante a la música, es el marco histórico en el que Kepler participaba de una experiencia estética totalmente nueva, con respecto, tanto a la música de los antiguos, como al sentido del dogma. La polifonía contemporánea poseía para Kepler tal complejidad y belleza que se convirtió en un ejemplo palpable de lo que podía producir el arquetipo geométrico divino. De alguna manera, el estudio, y seguramente, la audición de obras polifónicas, en especial, las de Orlando di Lasso, estimularon en Kepler la contemplación de un tipo de complejidad y emotividad, que asumió, similar a la de las órbitas celestes. Su teoría musical, junto a la obra polifónica de sus contemporáneos, resultó un auténtico "laboratorio armónico-astronómico-teológico", donde poner a prueba la verdadera naturaleza del universo. Fue tal el convencimiento que poseía Kepler de que ambas disciplinas, música y astronomía, provenían de un mismo arquetipo, que se permitía explorar en una para conocer de la otra. Kepler lo afirmaba escribiendo que

94 Con el término Musica Poetica, los tratadistas del barroco alemán intentaron englobar, básicamente, dos temas: la fundamentación matemática de la música con la capacidad de conmover los espíritus y corazones de los oyentes. A este respecto, estudiaron la relación entre la música y las palabras basándose, tanto en las matemáticas como en la oratoria y la retórica. Joachim Burmeister (*Lüneburg, 1566; †Rostock, 1629) sistematizó estas ideas en su tratado Musica Poetica, en el cual estableció un primer vocabulario de figuras musicales - ornamenta-, a la manera de la retórica clásica, y como elementos de análisis y composición musical. Para ello, Burmeister utilizó como ejemplo, varios motetes de Orlando di Lasso, entre los cuales destacaba el ya mencionado In me transierunt. BURMEISTER, 1606. Hay traducción al inglés en BURMEISTER, 1993. Para una introducción general al tema de las relaciones entre música y retórica en el barroco alemán, véase BARTEL, 1997. 
[...] Mens humana,judicium auditusinformans, instinctu naturaliCreatorem imitetur, delectu et approbatione proportionum in vocibus earundem, quae Deo placuerunt in attemperatione mottum coelestium. ${ }^{95}$

En esta cita puede corroborarse, una vez más, que la afinidad que hallaba Kepler entre la música y los movimientos celestes, no operaba sólo racionalmente, sino que se encontraba, también, en el plano de la experiencia estética. Así, el deleite musical era equivalente al astronómico, y ambos, lo eran al placer que siente el Creador.

Pero, ¿por qué hace Kepler esto en este momento histórico? Está claro que estas conexiones ya las habían hecho otros filósofos e incluso, artistas y humanistas -larga sería la lista a enumerar-, pero, como se ha visto, la razón que se ha ofrecido es un alegato al espíritu de su tiempo y puede ser expuesta de forma clara y distinta: sus contemporáneos músicos han podido comprender con claridad el arquetipo en sus composiciones musicales. La belleza, la complejidad y el grado de conmoción que producen son similares a los que produce el espectáculo celeste y si los músicos han logrado comprender y "recrear" el arquetipo, él, como "astrónomo" también puede hacerlo. Ése fue el plan, y a lo largo de su obra, Kepler recordaba constantemente su presente cultural musical al colocar a la invención reciente de la polifonía y la música de Lasso como el contexto verdadero donde se justificaban sus formulaciones teóricas. Este "presentismo cultural", otorgaba veracidad a las manifestaciones culturales de su contemporaneidad, y se alejaba en la misma proporción de las propuestas antiguas que no le acompañaban. Los juicios keplerianos podrían verse como una efusión lírica de un melómano o aficionado a la música y la astronomía, pero cuando se sabe que viene de su voz, debe reconocerse que tras él, había interminables horas de reflexión ancladas en una sólida formación que incluía lo musical en primera línea.

Todo esto permite afirmar que, a lo largo de los años que discurren, desde los primeros bocetos del Harmonices Mundi en 1599, hasta el año de 1619, Kepler incorporó al grueso de su sapiencia un cúmulo de experiencias musicales y estéticas -junto al instrumental teórico y técnico- que le permitieron afrontar lo que su obra quería demostrar: que la estructura del universo no era un bloque geométrico estático, sino que, siendo dinámica, se comprendía de acuerdo a las proporciones armónicas deducidas de la geometría del círculo, escuchadas en la cuerda sonora y, en general, de la música que, igualmente, es dinámica, transcurre en el tiempo e inunda el espacio.

En esta estructura armónica, una virtud motriz que emana del Sol hace que sus componentes aceleren y desaceleren, se alejen y se acerquen para configurarse de una única manera posible. Este todo, armonioso y dinámico, ha sido concebido con la "belleza a la que nos tiene acostumbrado Dios" y la polifonía musical de un Orlando di Lasso ha mostrado el ejemplo perfecto de cómo el arquetipo geométrico se expresa de igual manera, es decir: con escalas mayores y menores, con melodías correctas en imitación y contrapunto, con diminuendos y crescendos, acelerandos y ritardandos, y, finalmente, con una sensual belleza autosuficiente.

95 " $[. .$.$] la mente humana, ajustando su juicio a lo que escucha, por instinto natural imita a El Creador mostrando placer$ y aprobación por las mismas proporciones en las notas con las cuales Dios se ha complacido en el arreglo de los movimientos celestes.” KEPLER, 1619, III: 2; 1937, vol. 6: 93; 1997: 129. 


\section{BIBLIOGRAFÍA}

ARTUSI, Giovanni Maria, L'Arte del contrapont,o ridotta in tavole, Venecia, G. Vincenzi y R. Amadino, 1586.

BARKER, Andrew, Greek Musical Writings, Vol.II, Harmonic and Acoustic Theory, Cambridge, Cambridge University Press, 1989.

BARTEL, Dietrich, Musica Poetica: Musical-Rhetorical Figures in German Baroque Music, Lincoln, University of Nebraska Press, 1997.

BURMEISTER, Joachim, Musica Poetica, Rostock, S. Myliander, 1606.

BURMEISTER, Joachim, Musical Poetics, Benito Rivera (trad.), New Haven, Yale University Press, 1993.

BUSZIN, Walter, The Musical Quarterly, 32/1 (Oxford, 1946).

CALDERÓN, Carlos, Experiencia estética y formulación científica: el caso del Harmonices Mundi de Johannes Kepler, Trabajo de Investigación (DEA), Barcelona, Universitat Pompeu Fabra, 2005.

CASPAR, Max, Johannes Kepler, Stuttgart, Kohlhammer, 1941.

CASPAR, Max, Kepler, Madrid, Acento Editorial, 2003.

COMANINI, Gregorio, Il Figino overo del fine della Pintura, Mantua, Francesco Osanna, 1591.

DICKREITER, Michael, Der Musiktheoritiker Johannes Kepler, Berna, A. Francke AG, 1973.

GALILEI, Vincenzo, Dialogo della musica antica et della moderna, Florencia, Giorgio Marescotti, 1581.

GOZZA, Paolo, (ed.), Number to Sound: The Musical Way to the Scientific Revolution, Reihe, The Western Ontario Series in Philosophy of Science, 2000.

HAUSER, Arnold, Mannerism: The Crisis of the Renaissance and the Origin of Modern Art, Michigan, Routledge \& Paul, 1965.

HAUSER, Arnold, Pintura y manierismo, Madrid, Guadarrama, 1972.

KEPLER, Johannes, Prodromus dissertationum cosmographicarum, continens mysterium cosmographicum, Tübingen, Georgius Gruppenbachius, 1596.

KEPLER, Johannes, Strena, seu de Nive Sexangula, Frankfurt, Godofredo Tampachii, 1611.

KEPLER, Johannes, Harmonices Mundi, Linz, Godofredi Tampachii, 1619.

KEPLER, Johannes, Gesammelte Werke, Max Caspar, (ed.), 20 vols. Munich, Beck, 1937 - en curso.

KEPLER, Johannes, El Secreto del Universo, Madrid, Alianza Editorial, 1992.

KEPLER, Johannes, The Harmony of the World, Eric Aiton, Allistair Duncan y Judith Field, (trads.), Philadelphia, American Philosophical Society, 1997.

KOESTLER, Arthur, The Sleepwalkers, Londres, Hutchinson Publishing Group, 1959.

KOESTLER, Arthur, Kepler, Barcelona, Salvat, 1985.

KUHN, Thomas, The Essential Tension, Chicago, The University of Chicago Press, 1977.

KUHN, Thomas, La Tensión Esencial, México DF., Fondo de Cultura Económica, 1982.

LINDELL, Robert, Music in the German Renaissance: sources, styles, and contexts. John Kmetz, (ed.), Cambridge, Cambridge University Press, 1994. 
LISTENIUS, Nicolaus, Rudimenta Musicae in gratiam studiosae juventutis diligenter comportata A. M. Nicolao Listeni, Wittenberg, Georgium Rhau, 1533.

LUTERO, Martin, Luthers Werke in Auswahl, Berlín, De Gruyter, 1959 - 1967.

MAIER, Michael, Atalanta Fugiens, hoc est, Emblemata Nova de Secretis Naturae Chymica, Oppenheim, Johann Theodor de Bry, 1617.

MAIER, Michael, La fuga de Atalanta (CD), Girona, Atalanta, 2007.

NEWTON, Isaac, Principios matemáticos de la filosofía natural, Madrid, Alianza Editorial, 1987.

PANTALEON, Heinrich, Prosopographia heroum atque illustrium virorum totius Germaniae, Basilea, Nicolaus Brylinger, 1565.

RAMEAU, Jean Philippe, Traité de l'harmonie réduite à ses principes naturels, Paris, Ballard, 1722.

SHAPIN, Steven, La Revolución Científica: una interpretación alternativa, J. Romo, (trad.), Barcelona, Paidos, 2000.

STEPHENSON, Bruce, The Music of the Heavens, Kepler's Harmonic Astronomy, Princeton, Princeton University Press, 1994.

TARAZONA, Andrés Ruiz, Historia de la música, Vol.1, La música en la cultura griega y romana, Madrid, Turner, 1994.

WALKER, Daniel Pickering, Studies in musical science in the late Renaissance, Londres, Warburg Institute, 1979.

ZARLINO, Gioseffo, Le Istitutioni Harmoniche, Venecia, Francesco Franceschi, 1558.

Recibido: 05/03/2012

Aceptado: 21/02/2013 